\title{
Business transformation towards sustainability
}

\author{
Anna-Luisa Müller • Regina Pfleger
}

Published online: 19 July 2014

(C) The Author(s) 2014. This article is published with open access at Springerlink.com

\begin{abstract}
Sustainability is becoming increasingly important in today's corporate world and can contribute to the current and future success of organizations. Integrating ecological, social, and economic objectives into corporate decisions is a key success factor for transformation towards sustainability. As sustainability is not achieved by single actions, but rather is an on-going process, decision-makers must have means to analyze the current state of an organization. For this, we first illustrate how companies can structure the field of action for the transformation towards sustainability. Furthermore, we propose a decision model to determine how sustainability actions should be implemented in accordance with the paradigm of value-based management, i.e., considering their economic effects. We illustrate the application of the approach using the example of a German medium-sized company.
\end{abstract}

Executive summary Recently, organizations have recognized sustainability as an emerging mega-trend and as an increasingly important strategic goal. Its integration into the business model can be a key success factor, but also a challenge that requires a systematic approach. In order to comprehensively steer corporate sustainability, with the aim of minimizing negative externalities while maximizing positive effects, companies first need to structure their processes to achieve transparency on where sustainability actions can be incorporated. By furthermore considering the three dimensions of sustainability, possible starting points for sustainability actions can be identified. These two perspectives are complemented by adapting the basic idea of stages of development and maturity to sustainability context, as a way to capture the progress of sustainability actions within each corporate activity. The resulting "Sustainability Maturity Cube" serves as a blueprint, i.e., a first generic approach, of how an organization can structure

Responsible editor: Sönke Albers (Marketing).

A.-L. Müller · R. Pfleger ( $₫)$

FIM Research Center, Universitätsstraße 12, 86135, Augsburg, Germany

e-mail: regina.pfleger@fim-rc.de

A.-L. Müller

e-mail: anna-luisa.mueller@fim-rc.de 
the field of action for the transformation towards sustainability. Considering the paradigm of value-based management in business context, economic effects of the transformation towards sustainability have to be regarded. We therefore, also propose a decision model, which allows aligning ecological, social and economic objectives in order to draw economically useful conclusions by determining the optimal increase of the sustainability maturity level. To evaluate whether our approach proves useful for subject matter experts who are involved in sustainability decisions, we provide a first example of how a specific company can transform towards sustainability.

Keywords Sustainability - Corporate sustainability · Economic valuation · Transformation · Decision-making $\cdot$ Triple bottom line $\cdot$ Sustainability maturity level

\section{JEL-classification $\quad \mathrm{F} 64 \cdot \mathrm{M} 14 \cdot \mathrm{Q} 56$}

\section{Introduction}

In recent years, sustainability issues have gained increasing attention and importance. A 2009 survey of 224 business leaders worldwide showed that $60 \%$ of them believe that ecological and social responsibility has increased in importance over the past years (Hiddleberger and Hittner 2009). A MIT Sloan Management Study on sustainability further revealed that two-thirds of the 4.700 respondents agree that sustainability is essential to competitiveness and nearly three quarters agree that sustainability is a permanent part of their agenda and that their commitment will further increase (Kiron et al. 2012). Many examples like the immense global $\mathrm{CO}_{2}$ emissions, dwindling resources, child labor as well as the increasing gap between the richest and the poorest show that the consequences of our current way of living cause not only ecological but also social problems in the industrialized and developing countries (Lowe 1998).

Not only scarce resources and the emerging social problems, but also expectations of stakeholders of a company like its customers, investors, employees, suppliers or society in general intensify the pressure on companies to integrate sustainable issues in their business. Companies need to manage these challenges to benefit from the transformational power of the development and thus make "sustainability" a key success factor (Hahn and Scheermesser 2006). Hence, its integration into the core business, i.e., business strategy, business model, and the value generating processes and products is required (Porter and Kramer 2006; Schaltegger and Müller 2008). Starting at strategy level, several types of sustainability strategies exist (Hardtke and Prehn 2001; Schaltegger et al. 2002; Baumgartner 2005). We distinguish introverted sustainability strategies (risk mitigation focusing on fulfilling legal and other external standards), extroverted sustainability strategies (legitimating approaches focusing on external relationships), conservative sustainability strategies (focusing on eco-efficiency) and visionary sustainability strategies (holistic approaches focusing on sustainability issues within all business activities) (Baumgartner and Ebner 2010). With regards to 
the business model and the underlying value generating processes and products, a wide range of management tools for implementing and measuring corporate sustainability has been developed (Schaltegger et al. 2002). As sustainability issues are being more and more institutionalized (Bansal and Bogner 2002; Bansal and Roth 2000; Prakash 2001) there are standardized management systems, guidelines and official recommendations for environmental and social reporting, tools for the measurement of corporate sustainability and applied concepts, which try to facilitate the integration of sustainability into organizations (please refer to Appendix 1 for an overview on exemplary selected tools and management approaches). Tools for the measurement of corporate sustainability focus on controlling and managing the operationalization of sustainability strategies (Atkinson 2000; Figge and Hahn 2004a, b; Huizing and Dekker 1992; Kaptein and Wempe 2001). The most prominent examples of sustainability measurement systems are the Sustainability Balanced Scorecard and sustainability maturity models: the first posits that for companies to contribute to sustainable development, it is desirable that corporate performance improves in all three dimensions of sustainability-economic, environmental, and social-simultaneously (Figge et al. 2002). Also the basic idea of (sustainability) maturity models, i.e., the concept of stages or levels of development, can be used to objectively evaluate a company's state with regards to sustainability and thus provides organizations a sensible tool to manage their sustainability capability (Becker et al. 2009; Kazanjian and Drazin 1989). The variety of tools and concepts shows the wide range of possibilities a company has for integrating sustainability into its business. It is therefore vital to structure the field of action by identifying where to start implementing sustainability (i.e., concrete possible starting points), what to do (exemplary sustainability actions) and where these actions have the greatest impact. Accordingly, our first research question is:

1. To transform towards sustainability, how can decision-makers structure the field of action?

Although there are many studies concerning sustainable management, the overall economic effect of sustainability actions over all dimensions has not been investigated in detail yet. With the effects of ecological and particularly social actions being difficult to valuate, decision-makers tend to neglect the economic consequences of sustainability actions as long as there is no structured approach for decision-making. It is thus the question how sustainability actions should be implemented in accordance with the paradigm of value-based management, i.e., considering economic effects. This leads to our second research question:

2. To transform towards sustainability, how should sustainability actions be implemented in accordance with value-based management, i.e., when considering their economic effects?

To answer the first research question, we show how one can structure an organization's processes exemplarily using Porter's value chain (1985) with the aim of achieving transparency on where sustainability actions can be incorporated. By furthermore considering the three dimensions of sustainability, we propose possible 
sustainability actions, i.e., we provide exemplary ideas on how to improve working conditions in production processes (social perspective) or optimization of delivery routes (ecological perspective) for instance. We complement these two perspectives (1st corporate activities; 2nd dimensions of sustainability) by additionally introducing a way to capture the progress of sustainability actions, adapting the basic idea of stages of development and maturity to sustainability context. The resulting Sustainability Maturity Cube serves as a blueprint, i.e., a first generic approach, of how an organization can structure the field of action for the transformation towards sustainability. It can build the basis for the instantiation of concrete sustainability maturity models and for deriving corporate actions. We answer the second research question by adapting the decision model based on Kamprath and Röglinger (2011), who conveyed the principles of value-based management to decision-making with process maturity models. We oppose costs and benefits of sustainability actions in order to determine how sustainability actions should be implemented considering their economic effects.

With the Sustainability Maturity Cube as a blueprint and the decision model at hand, we contribute to theory and practice: first, we combine already existing and acknowledged scientific concepts, such as Porter's value chain and maturity models, and adapt them to a new problem context, i.e., business transformation towards sustainability. Second, our approach provides organizations with decision-support as it, besides structuring their field of action, aligns decisions regarding the transformation towards sustainability with the paradigm of value-based management, taking into account the ambiguous role of the economic dimension in business context.

The remainder of this paper is organized as follows: Sect. 2 provides theoretical background on sustainability, corporate sustainability, and the idea of maturity models. In Sect. 3, we structure the field of action for the transformation towards sustainability. The resulting Sustainability Maturity Cube illustrates the coherence of sustainability maturity levels, i.e., the state of development or progress, the corporate activities and dimensions of sustainability, respectively. Following these elaborations, the decision model of Kamprath and Röglinger (2011) is extended and adapted for the economic valuation of sustainability actions in Sect. 4. Section 5 exemplarily demonstrates the applicability of the approach. In Sect. 6 we briefly summarize the key findings and provide topics for future research.

\section{Theoretical background}

\subsection{Sustainability: a multidimensional construct}

Sustainability and sustainable development (we use both terms synonymously in this paper) have been extensively discussed in academia and practice. As a broad range of aspects can be subsumed under the term sustainability, there is no common understanding and numerous definitions exist (Kastenholz et al. 1996; Ruhwinkel 2013). Also Koplin (2006) concludes that it is impossible to find a globally uniform definition that holds true for all actors and situations. Grounded already in the 
seventeenth century with a resource-focused, i.e., ecological understanding (overexploitation of forests), the term sustainability has broadened its focus over the last decades. Today's understanding of sustainability derives from the international conferences on environmental issues starting in the 1960s and 1970s. Prominent examples are the report "The Limits of Growth" of the Club of Rome in 1972 and the Brundtland Report "Our Common Future", which was published by the World Commission on Environment and Development (WCED) in 1987. While the Club of Rome focused on the long-term consequences of consumption and production patterns like population growth and environmental pollution, the WCED gave the first substantial impulse for sustainable development by defining sustainability as a "development that meets the needs of the present without compromising the ability of future generations to meet their own needs" (WCED 1987, Chapter 2, p. 1). Sustainability actions can have social (e.g., concerning the equality of opportunities), environmental (e.g., concerning the quality of the eco-system), and economic (e.g., concerning a stable and healthy economy to ensure living conditions) implications. These three dimensions represent the three main pillars of sustainability and are also known as the "triple-bottom-line" concept (Elkington 1997). Whereas the success of the Brundtland definition stems from its opacity and its applicability in a growth context (Goodland 1995), also other definitions of sustainability (e.g., Ferguson et al. 2003; Epstein 2008) have the preservation and improvement of the economic, ecological, and social system for the benefit of existing and future generations in common.

The triple-bottom-line concept and the understanding of sustainability in the Brundtland Report furthermore share the belief that sustainable development requires implementing all dimensions, i.e., all pillars of sustainability equally and at the same time, as they are complementary, but not interchangeable. This concept can be described by the term strong sustainability (Figge et al. 2001). In contrast to that, weak sustainability is based on a theory within ecological economics saying that the different existing sorts of capital, i.e., human (social dimension), natural (ecological dimension) or manufactured capital (economic dimension) can be substitutes for each other (Ciegis et al. 2009). Weak sustainability thus does not account for possible negative externalities (e.g., consequences of consumption of dwindling resources) caused by the substitution with capital.

The parallel implementation of all dimensions of sustainability can be complementary or rival. As targets in the social or ecological dimension are not necessarily targets from an economic perspective, there may result conflicts, especially in a short-term view. However, these conflicts tend to resolve in the longrun. For example, keeping old technologies and realizing (short-term) economic savings, despite the existence of better solutions and hence causing higher environmental pollution, might result in customer dissatisfaction due to nonconformity with expected ecological behavior and thus decreasing sales that precipitate in the long-term. Ruhwinkel (2013) accordingly concludes that on a high level of aggregation, economic, ecological, and social developments are seen as an inner unity. Nevertheless, the difficulties regarding a clear definition, understanding and thus operationalization of sustainability show that sustainable development is a 
complex and multidimensional issue, which has to combine efficiency, inter- and intra-generational equity on an economic, social, and environmental ground (Ciegis et al. 2009; Ruhwinkel 2013). Thereby an "either or"-decision as well as the unyielding understanding of concepts like strong sustainability are not sufficient or too inflexible to describe the existing challenges and opportunities within this context. In this paper, we do not stick to one particular concept but follow the comprehensive but rather simplifying understanding of sustainability as a multidimensional concept that aims at ensuring or improving today's living standards including ecological, social, and economic aspects. Thereby, negative externalities need to be prevented or kept to a minimum while positive externalities need to be encouraged and supported. With the different dimensions of sustainability being mutually dependent, from our point of view the most important challenge is to decide which solution is the best trade-off between the rivaling or synergetic dimensions in each individual situation. Yet, in business context this is especially challenging as the economic dimension is of particular importance in conformity with the paradigm of value-based management.

\subsection{Corporate sustainability}

In accordance with Freeman's stakeholder theory (Freeman 1984), researchers agree that companies have other responsibilities to their stakeholders besides economic issues (Salzmann et al. 2005). There are different concepts like corporate social responsibility (CSR), greening the business, eco-efficiency or eco-advantage (Schmidt et al. 2010) to address these responsibilities. Thereby, sustainability actions should be related to the context of the business, i.e., they should address issues of what is produced (products, services), how it is produced (processes), by whom (people), and its implication for stakeholders (Robinson et al. 2004).

However, what is the financial pay-off to seek justification for sustainability actions (Salzmann et al. 2005, p. 27)? The business case of sustainability has gained in importance-and companies face a dilemma. In accordance with the paradigm of value-based management, the consideration of costs, benefits and risks when deciding on an investment is necessary, plausible, and an accepted standard. The same needs to hold true for sustainability context. Investments in sustainability actions normally mean financial burdens at least in a short-term view, which do not, or if at all, might only pay-off, e.g., due to the fulfilment of stakeholder needs in the long-run (for example meet expectations of consumer groups like LOHAS [Life of Health and Sustainability (Ray and Anderson 2000)], green investment, $\mathrm{CO}_{2}$ emission certificates). Hence, securing survival in a market economy and at the same time integrating sustainability and "being good" or "being as sustainable as possible" does not necessarily resolve at first sight. It is impossible to give universally valid managerial advice on how to deal with conflicts between sustainability dimensions, the economic perspective however is of particular importance and can be seen as "ambiguous" in business context. Even though conflicts tend to dissipate in the long-run according to Ruhwinkels' (2013) goal congruence of the three sustainability dimensions on a high aggregation level, an economic valuation is indispensable in accordance with value-based management as 
guiding principle. Thereby, the paradigm of value-based management implies that also long-term effects are considered in the valuation. Our understanding of corporate sustainability hence implies that the economic dimension needs to be treated with a special focus: on the one hand it is one of the three pillars of sustainability, but at the same time, as companies need to follow economic principles to survive in competition and to achieve long-term business success, it emerges as an additional organizational incentive when engaging in sustainability transformations (Seidel et al. 2010). This differentiates the economic dimension from the other two dimensions of sustainability.

\subsection{Stages of development and maturity}

Based on the assumption of predictable patterns of organizational evolution and change, maturity models typically represent theories about how an organization's capabilities evolve in a stage-by-stage manner along an anticipated, desired, or logical path from an initial state to maturity (van den Ven and Poole 1995; Kazanjian and Drazin 1989). Accordingly, they are also termed stages-of-growth models, stage models, or stage theories (Prananto et al. 2003). In a wider definition, a maturity model is a management artifact that supports the systematic improvement of a complex, multi-faceted process or function-such as sustainability management. In a much narrower definition, maturity models are regarded as synonyms for assessment artifacts like, e.g., the Capability Maturity Model Integration (CMMI) proposed by the Software Engineering Institute at Carnegie Mellon University (Paulk et al. 1993). Maturity models apply different stages of development or maturity as a measure to evaluate the capabilities of an organization in regards to a certain discipline, and thus provide a framework for prioritizing improvement actions that are meaningful to the organization (de Bruin et al. 2005; Iversen et al. 1999). The objective is hence to assess the as-is situation, to incrementally build skills and capabilities, and to outline the stages of maturation paths in order to diagnose and eliminate deficient capabilities (Rummler and Brache 1990). Thereby, the maturity levels indicate an organization's current (or desirable) capabilities with regard to a specific class of entities (objects, application domains) (Rosemann and de Bruin 2005) meaning that if those capabilities are fulfilled, a certain level of maturity is achieved. By starting to look at single activities, companies can appraise their capability stage by appraising their existing process, so their performance indicators such as productivity, profitability, or customer satisfaction can be improved. For the remainder of this paper, the wider understanding of maturity models is of particular relevance to us as, with the Sustainability Maturity Cube, we intend to provide a blueprint that supports business transformation towards sustainability on a conceptualization level by structuring the field of action.

There now exist more than 150 different maturity models in various domains of application (de Bruin et al. 2005) and also some that can be applied to describe the transformation towards sustainability (please refer to Table 5 in the appendix for an exemplary range of sustainability maturity models found in literature). The focus of sustainability maturity models is on providing a scheme that supports the development, establishment, and persecution of a sustainability strategy for a 
company (Baumgartner and Ebner 2010). In literature, the terms sustainability maturity model and sustainability capability maturity model are used synonymously. We use the notion sustainability maturity model throughout the remainder of this paper. Sustainability maturity models basically apply a slight modification of the maturity levels of the CMM or CMMI, respectively, to define a five-level maturity grid: at level 1 sustainability maturity is initial, there is little understanding of the subject and few or no related policies. Level 2 stands for a rudimentary level. Companies begin considering sustainability aspects in corporate decision-making, which means that-if existing-only mandatory rules and laws are respected. Maturity level 3 marks an elementary integration of these aspects into corporate strategy. In compliance with sustainability-related laws the organization has developed capabilities and skills and encourages individuals to contribute to sustainability programs. Level 4 represents a satisfying consideration and maturity of the specific sustainability aspect (often above the industry average). Sustainability is a core component of the business planning life cycles. Sophisticated maturity is defined by level 5, which implicates an outstanding effort towards sustainability. The organization employs sustainability practices across the entire enterprise and includes customers, suppliers, and partners. The industry recognizes the organization as a sustainability leader and uses its sustainability maturity practices to drive industry standards (Baumgartner and Ebner 2010).

\section{Structuring the field of action}

To structure the field of action for the transformation towards sustainability, we need a conceptual framework to cover a holistic view of an organization's business model. By this means, we can capture and systematize those corporate activities (1st perspective) which might be critical for the value creation, i.e., the success of a company. For all identified corporate activities, we furthermore add the perspective sustainability (2nd perspective) to enable analyzing the current state of sustainability, compartmentalized in its three dimensions (social, ecological, and economic). As a result, we are able to illustrate exemplary starting points for sustainability actions (Table 1) for the transformation towards sustainability in each corporate activity and for each dimension of sustainability. By adding sustainability maturity levels as a third perspective to the resulting Sustainability Maturity Cube (Fig. 1), we offer a blueprint that allows for describing different stages of development or progress for all sustainability actions.

\subsection{Identification and systematization of starting points for the transformation towards sustainability}

To identify adequate starting points for integrating sustainability, one needs to analyze the business system as a whole. By systemizing corporate activities (and underlying processes, respectively) and the three dimensions of sustainability, we enable the application of sustainability maturity models to valuate transformation options on the most granular stage of a business system. Therefore, we 
systematically identify and illustrate those factors that may represent critical success factors for value creation and hence starting points for transformations towards sustainability.

There are various frameworks that support identifying core corporate activities: Rosemann and de Bruin (2005) for example name "strategic alignment", "culture", "people", "governance", "methods" and "IT" as critical success factors that influence process success and hence business success, respectively. Osterwalder and Pigneur (2002) present nine building blocks to describe or build a company's business model, i.e., how an organization creates, delivers, and captures value (Osterwalder and Pigneur 2002): key partners, key resources, key activities, key relationships, customer segment, channels, revenue streams, value propositions, and cost structure. Analogously, Porter's value chain (1985) helps to identify and structure those activities, which lead to a company's competitive advantage. It enables the separation of the business system into a series of single strategic relevant activities that are value generating by distinguishing primary value chain activities and support activities. The primary activities are divided into the categories inbound logistics, operations, outbound logistics, marketing and sales, and service. These activities are directly related to the physical creation of a product, its sale and transfer to the customer as well as to the aftersales assistance. Thereby, all these activities are directly affecting customers' perception and thus, the accumulation of value for the certain product or service, or for the company in total. As this methodology is highly known and recognized by researchers and practitioners (Sanchez and Heene 2003), it builds the basis of our blueprint. However, Porter's value chain is just an exemplary framework to structure the field of action, and can be replaced by any other framework. Especially when focusing, e.g., on the service sector, other frameworks which are not designed primarily for production issues could be used in order to account for inherent industry specifics. Independently of the respective industry though, the general framework of Porter's value chain has to be adapted to each company individually (Porter 1985). Table 1 lists the primary and support activities (thereafter referred to as corporate activities) following Porter (1985) in the lines. This first perspective indicates where in the value chain companies can start the transformation towards sustainability. Adding the three dimensions of sustainability as second perspective further allows specifying these starting points. Thereby, several frameworks can provide support like the Global Reporting Initiative's G4 Sustainability Reporting Guidelines (GRI-guidelines) or Silvius and Schipper (2010) who suggested a checklist for successfully integrating sustainability in projects and project management. Although several other reporting guidelines have emerged like the OECD Guidelines for Multinational Enterprises (OECD 2011) or the UN Global Compact "Ten Principles" (United Nations Global Compact 1999), the GRI-guidelines are the most comprehensive and recognized standard (Brown et al. 2009; Global Reporting Initiative 2013). They provide an intuitive and clear overview to introduce and classify exemplary starting points for the transformation towards sustainability. In our paper, we thus follow these guidelines.

After having proposed a way to identify and systemize possible corporate activities and related starting points for transformation towards sustainability, in the 


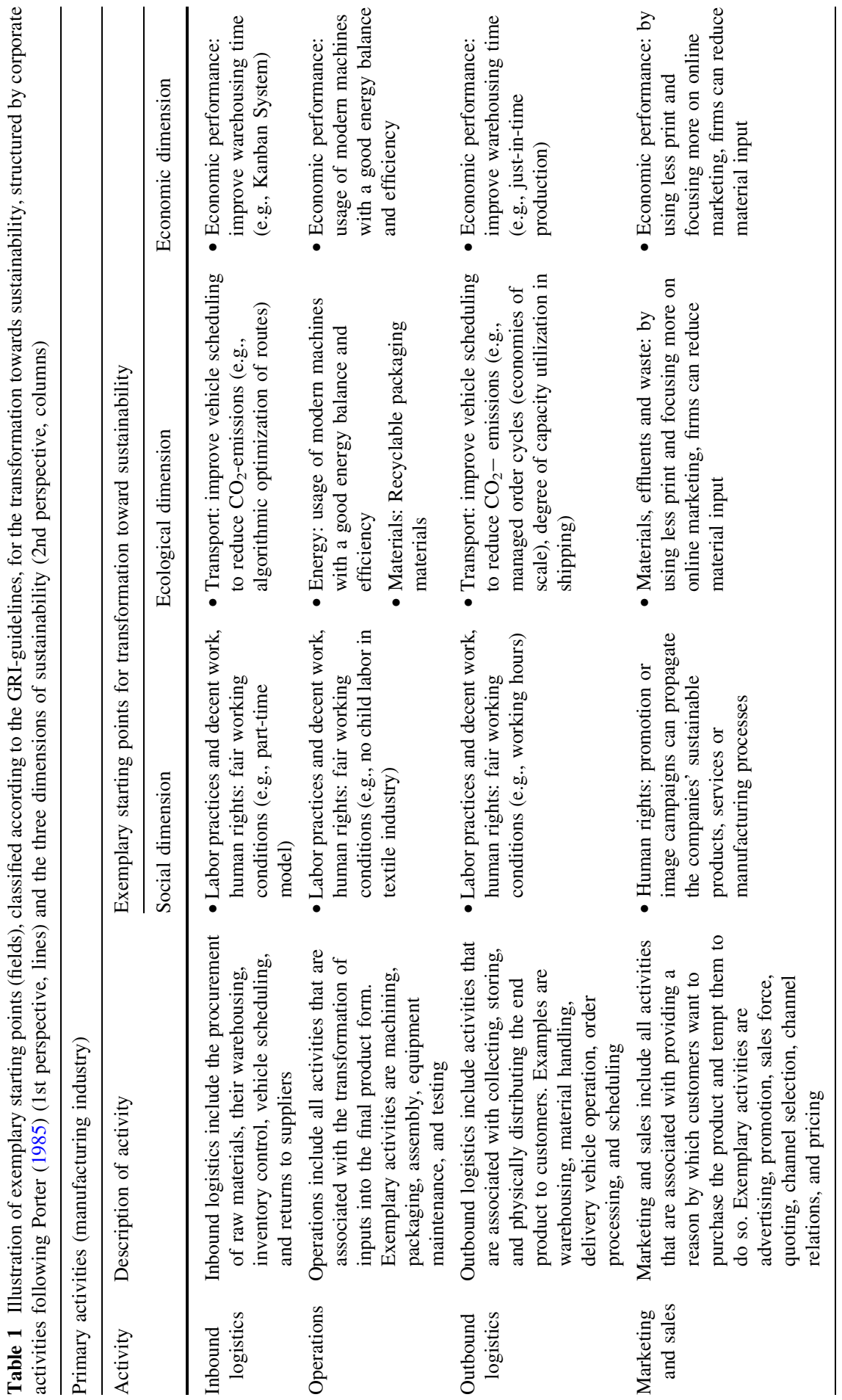




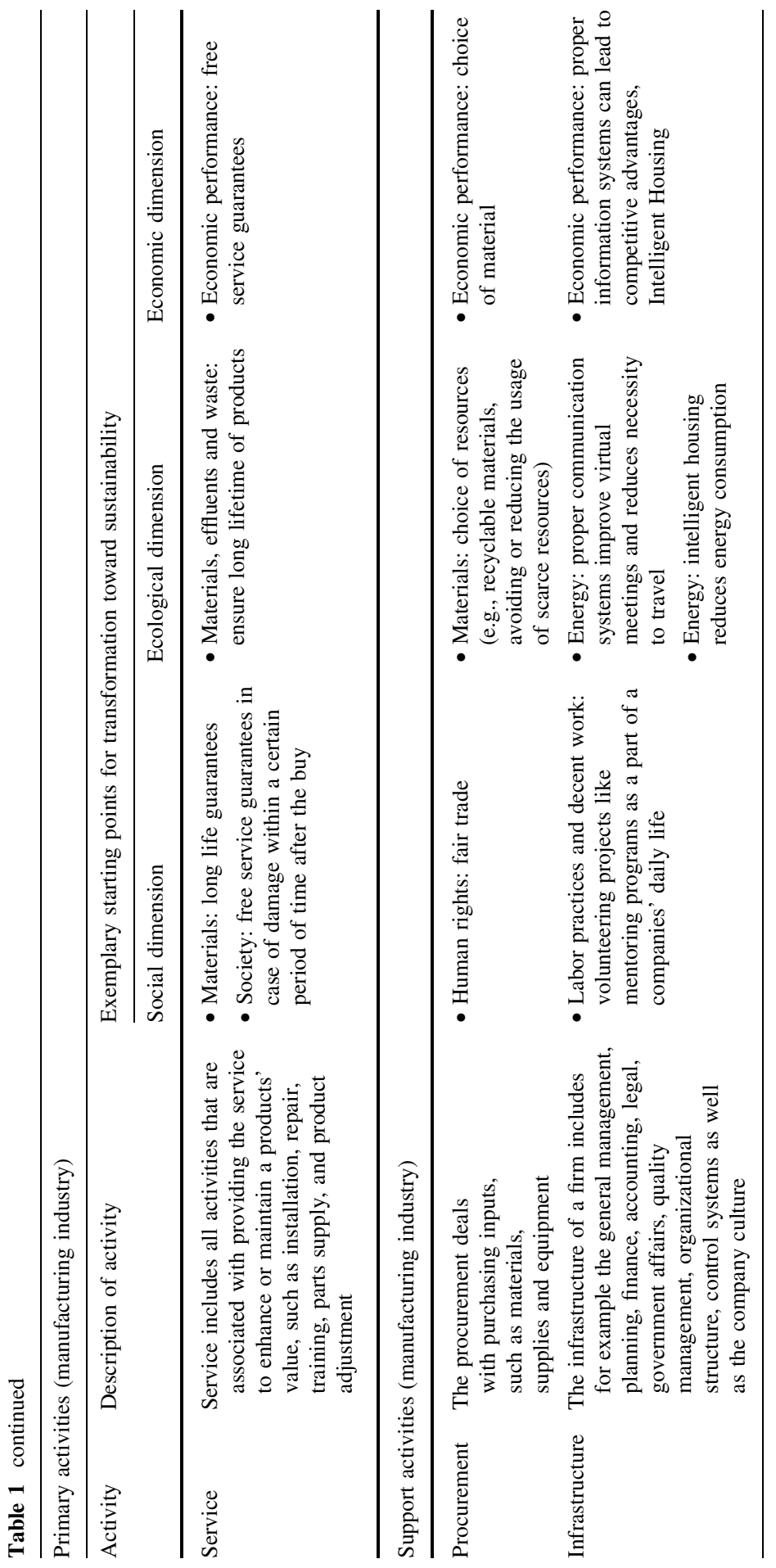




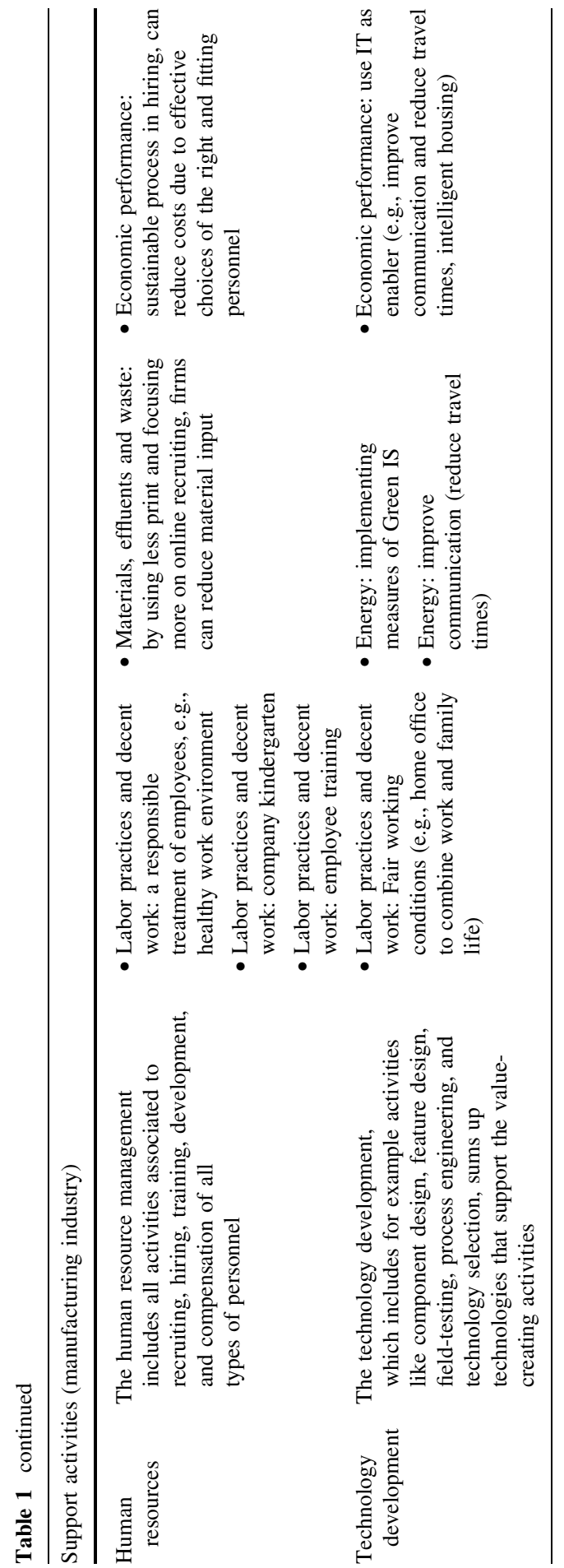


next step the underlying processes and hence their specific possible transformation need to be analyzed. By doing so, one can define current stages of development and achieve transparency regarding definite and necessary actions which have to be implemented in order to reach a targeted stage. For this, we propose sustainability maturity models that enable describing current and targeted sustainability maturity levels.

\subsection{The sustainability maturity cube}

Depending on the progress and strength of the transformation towards sustainability in the respective company, different stages of development within each sustainability dimension and corporate activity and hence within each starting point can be reached. A company that has already implemented sustainable actions at some stages could have achieved a certain level of maturity in some of the identified corporate activities and thus can improve its actual situation by further transformation.

Figure 1 summarizes the resulting Sustainability Maturity Cube. The perspectives, namely the corporate activities, the dimensions of sustainability and the according sustainability maturity levels form a cube that structures the possible field of action regarding transformations towards sustainability. One field of the cube represents the description of a certain sustainability maturity level in one of the three dimensions of sustainability for one identified corporate activity. Thereby, the Sustainability Maturity Cube can be seen as a blueprint that is based on acknowledged scientific concepts to support the systematic improvement of sustainability management by considering certain corporate activities, the three dimensions of sustainability and the corresponding stages of development. Of the three perspectives of the cube, only the operationalization of the dimensions of sustainability is fixed: our understanding of sustainability as a multidimensional concept that aims at ensuring or improving today's living standards including ecological, social and economic aspects leads to the three dimensions, i.e., ecological, social, and economic dimension. Regarding the other two perspectives, we only suggest applicable frameworks like Porter's value chain and maturity models, which are not further predefined, to describe the perspectives corporate activities and sustainability maturity levels, respectively. Hence, the Sustainability Maturity Cube provides the basic understanding and concept for transformations towards sustainability. It furthermore allows for developing concrete sustainability maturity models. At this point, we do not instantiate a concrete sustainability maturity model ourselves in order to keep the generic character of our approach. However, there are several issues that have to be considered when instantiating a concrete sustainability maturity model, such as the determination of current and targeted sustainability maturity levels, the formulation of concrete development paths from initial to desired maturity levels, the consideration of confounding effects (e.g., when implementing several actions at the same time) and situations when it makes sense to invest in a particular action or not. We address some of these issues in the real-world application of the Sustainability Maturity Cube in Sect. 5 and thus provide first insights in such an instantiation. We will now focus on our 
Fig. 1 "Sustainability maturity cube"

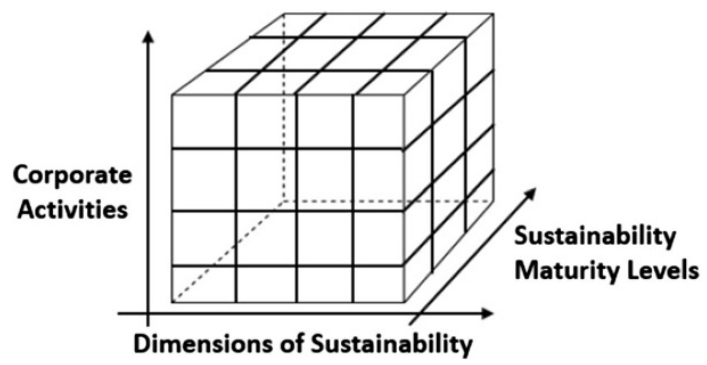

second research question: the overall economic valuation of the transformation towards sustainability.

\section{Decision model}

In accordance with value-based management, it is a main target of a company to identify the priority sustainability actions to improve on. To do so, based on the ideas of Kamprath and Röglinger (2011), the implementation of sustainability actions in order to increase sustainability maturity levels are regarded as investments. Kamprath and Röglinger (2011) analyze the general economic relationship of process improvement with maturity models and develop an economic decision model. The basic idea of the model is to consider the improvement of the maturity level as investment(s) with resulting cash in- and outflows. It is aim of the model to identify the configuration of improvement actions that maximize the total additional present value cash surplus. Consequently, the cash flows that come along with improvements of sustainability maturity levels have to be examined.

\subsection{Assumptions of the decision model}

In doing so, some prerequisites have to hold true: most maturity models are based on the assumption that maturity levels only take integer levels (Software Engineering Institute 2010) but in practice there might be maturity levels in between integer values. Hence, the underlying model uses real-valued maturity levels. Furthermore, determining the concrete monetary values of the consequences of sustainability actions may require applying approaches such as Power (2008) who for example measures the emerging benefits of investments that increase energy efficiency solely on the basis of utility values for environmental, social or economic benefits. Furthermore, we assume that some metrics can be estimated ex ante. However, being aware that this does not hold true for all metrics we elaborate on which metrics can be estimated and which cannot: There are numerous frameworks of sustainability assessment, which can provide assistance in determining such sustainability metrics. Most of the frameworks presented in Table 6 of the Appendix, e.g., the global reporting initiative, the environmental management 
systems, such as the ISO and EMAS standards or the study of the Center for Waste Reduction Technologies (CWRT) of AIChE (2004) provide a variety of possible sustainability indicators. While it is important to assess sustainability with several indicators, it may sometimes be difficult to make business decisions and comparisons among companies as these indicators are measured in very different units (Krajnc and Glavic 2009). Hence, sustainability indicators are helpful for decision-making, but need to be examined carefully for their use in decision models.

With regard to the different dimensions of sustainability, we find that all environmental problems can finally be traced back to physical and/or chemical interventions (Heijungs and Guinée 1992). Contrary, due to the great variety and diversity of social aspects and the lack of a common foundation in natural sciences as found for environmental aspects, it is very difficult to achieve a comprehensive classification of social aspects (Clarkson 1995). Even more, social aspects heavily depend on the preferences and values of the different actors involved (Zadek 1999). The stakeholder approach (Freeman 1984) for example provides a useful framework to classify the actors concerned with different social claims as it clarifies the interested groups and their wants and desires (Clarkson 1995; Figge et al. 2002).

\subsection{Formulation of the decision model}

Depending on whether a company already applies sustainability maturity models or not it may already has achieved a certain sustainability maturity level in the identified starting point for transformation towards sustainability $P_{i j}$ where there are $C_{i}(0 \leq i \leq n)$ identified corporate activities and $D_{j}(1 \leq j \leq 3)$ dimensions of sustainability. Thus, each of the $i \times j$ starting points has a current sustainability maturity level which is $m_{i j}^{\text {cur }} \in \mathbb{R}_{0}^{+}\left(m_{i j}^{\text {min }} \leq m_{j i}^{\text {cur }} \leq m_{j i}^{\max }\right)$, whereby $m_{i j}^{\text {max }} \in \mathbb{R}^{+}$ represents the highest achievable sustainability maturity level and $m_{i j}^{\min } \in$ $\mathbb{R}_{0}^{+}\left(m_{i j}^{\min }<m_{i j}^{\max }\right)$ is the lowest realizable sustainability maturity level. The sustainability maturity level of each starting point can be increased by $\Delta m_{i j}\left(0 \leq \Delta m_{i j} \leq m_{i j}^{\max }-m_{i j}^{\text {cur }}\right)$. An aggregation function $g\left(\overrightarrow{\Delta m}_{i}\right)$ with $\overrightarrow{\Delta m}_{i}=$ $\left(\Delta m_{i 1}, \Delta m_{i 2}, \Delta m_{i 3}\right)^{T}$ considers potential synergies or rivalries between the different dimensions of sustainability (e.g., higher costs for fair trade products in procurement) within one corporate activity. Additionally, there is a second aggregation function $f(\overrightarrow{\Delta m})$ with $\overrightarrow{\Delta m}=\left(\overrightarrow{\Delta m}_{1}, \ldots, \overrightarrow{\Delta m_{n}}\right)^{T}$ which aggregates the total sustainability maturity level regarding the synergies and rivalries between different corporate activities. Both functions will not be examined in detail in this paper (Kamprath and Röglinger 2011).

Implementing actions to improve sustainability (and thus the sustainability maturity level) requires investments $I$. These payments may differ from starting point to starting point and may not be necessarily completed in one period; therefore the net present value of the investment $I$ will be applied. Whereas small improvements of the sustainability maturity level can be implemented relatively straightforward, greater improvements of the sustainability maturity level are expected to require a more complex approach, which results in higher cash outflows. 
This relationship holds true, e.g., in project management or software engineering (Boehm et al. 2000) and also in the context of sustainable development as complexity will grow with more sophisticated actions. Additionally, it has to be taken into account that depending on the current sustainability maturity level for each starting point $\left(m_{i j}^{\text {cur }}\right)$ the investment payment $I$ differs, i.e., it grows positively related with the current value of $m_{i j}^{\text {cur }}$. Thus, a strictly monotonic increasing, strictly convex, and twice continuously differentiable function $I_{i j}^{\text {cur }}\left(\Delta m_{i j}\right) \in \mathbb{R}_{0}^{+}$(e.g., a quadratic function) can characterize the investment $I$ which is necessary for increasing the sustainability maturity level of each starting point $P_{i j}$ by a certain $\Delta m_{i j}$. The following equation can be applied:

$$
I_{i j}^{\mathrm{cur}}\left(\Delta m_{i j}\right)=I_{i j}\left(m_{i j}^{\mathrm{cur}}-m_{i j}^{\mathrm{min}}+\Delta m_{i j}\right)-I_{i j}\left(m_{i j}^{\mathrm{cur}}-m_{i j}^{\min }\right)
$$

Additionally to the investments $I$, the cash in- and outflows of the respective operational business have to be considered. There will be cash outflows $O$ to ensure the continuous implementation and the support for sustainability. The more sustainability actions are implemented the more complex the integration with existing actions (investments $I$ ) and the more difficult to maintain a high sustainability maturity level over a long period of time. Therefore, a strictly monotonic increasing, strictly convex, and twice continuously differentiable function $O_{i j}^{\text {cur }}\left(\Delta m_{i j}\right) \in \mathbb{R}_{0}^{+}$(e.g., a quadratic function) can be applied to characterize the cash outflows $O$ that come along with increasing the sustainability maturity level of each starting point $P_{i j}$ by $\Delta m_{i j}$.

Besides, there are other direct economic consequences resulting from the investment in sustainability for each starting point $P_{i j}$ : savings $S$. One example for these savings regarding the corporate activity "Human Resources" can be: By improving working conditions and thus employees' satisfaction, the fluctuation of employees (turnover rate) and thus the need to spend more on recruiting can be reduced (Arnold and Feldman 1982). A strictly monotonic increasing, strictly concave, and twice continuously differentiable function $S_{i j}^{\text {cur }}\left(\Delta m_{i j}\right) \in \mathbb{R}_{0}^{+}$(e.g., a root function) can characterize these direct savings $S$.

On the other side, the most important factor influencing the price and quantity of sales, i.e., cash inflows $E$ is the customers' willingness to pay. The customers and especially the aforementioned LOHAS (Lifestyle of Health and Sustainability) (Ray and Anderson 2000), are expected to be willing to pay more for a more sustainable product or service. These shifts in human attitude are difficult to trace but recent studies show that customers' mind-sets changed towards a more sustainability oriented direction: A survey conducted by market research group GfK suggests that consumers in five of the world's leading economies are turning to "ethical consumerism" (Grande 2007). Furthermore, consumers claim they would pay a 5$10 \%$ premium for ethical products even though a practical analysis shows that such brands have relatively small market shares (Grande 2007). Hence, if a company succeeds in satisfying the expectations of these customers, it positively affects their customer satisfaction (Matzler 2000), customer loyalty and reference potential, i.e., the number of potential customers that one customer can reach during his lifetime 
(Rudolf-Sipötz 2001). The named effects finally result in higher expected customer cash flows (Krafft 1999) and in an alteration of the customer lifetime value (CLV), which is the present value of all future profits generated from a customer (Gupta and Lehmann 2003). The CLV can thus be applied to estimate customers' reactions to sustainability actions. Furthermore, as the CLV is difficult to determine, the perception of the customers can also be evaluated by questioning the customers in structured surveys. As customers and especially LOHAS are assumed to be price sensitive we can assume a strictly monotonic increasing but — due to the diminishing marginal utility-strictly concave and twice continuously differentiable function $E^{\text {cur }}(f(\overrightarrow{\Delta m})) \in \mathbb{R}_{0}^{+}$(e.g., a root function) to characterize the cash inflows $E$ that come along with increasing the sustainability maturity level of each starting point $P_{i j}$ by $\Delta m_{i j}$. Summarizing, the following equations can be applied to determine the value of the resulting cash in- and out-flows for each starting point $P_{i j}$ :

$$
\begin{gathered}
O_{i j}^{\text {cur }}\left(\Delta m_{i j}\right)=O_{i j}\left(m_{i j}^{\text {cur }}-m_{i j}^{\text {min }}+\Delta m_{i j}\right)-O_{i j}\left(m_{i j}^{\text {cur }}-m_{i j}^{\text {min }}\right) \\
S_{i j}^{\text {cur }}\left(\Delta m_{i j}\right)=S_{i j}\left(m_{i j}^{\text {cur }}-m_{i j}^{\text {min }}+\Delta m_{i j}\right)-S_{i j}\left(m_{i j}^{\text {cur }}-m_{i j}^{\text {min }}\right) \\
E^{\text {cur }}(f(\overrightarrow{\Delta m}))=E\left(m^{\text {cur }}-m^{\text {min }}+f(\overrightarrow{\Delta m})\right)-E\left(m^{\text {cur }}-m^{\text {min }}\right)
\end{gathered}
$$

Finally, it is the question, which target determines the optimal improvements of the sustainability maturity level. In accordance with the principles of value-based management the regarded company strives for the maximization of the total additional payment surplus $\mathrm{CF}(\overrightarrow{\Delta m}) \in \mathbb{R}$. This results from the difference between the investment $I$ and the payment surplus of the cash outflows $O$ and cash inflows $S$ and $E$ :

$$
\begin{aligned}
\operatorname{MAX}: & \operatorname{CF}(\overrightarrow{\Delta m}) \\
= & -\sum_{i=1}^{n} \sum_{j=1}^{3} I_{i j}^{\mathrm{cur}}\left(\Delta m_{i j}\right)-\sum_{i=1}^{n} \sum_{j=1}^{3} O_{i j}^{\mathrm{cur}}\left(\Delta m_{i j}\right)+\sum_{i=1}^{n} \sum_{j=1}^{3} S_{i j}^{\mathrm{cur}}\left(\Delta m_{i j}\right) \\
& +E^{\mathrm{cur}}(f(\overrightarrow{\Delta m}))
\end{aligned}
$$

The initial optimal strategy is the one, which maximizes the expected value of the objective function given the initial beliefs. We solve this optimization problem by obtaining the derivatives of the function of the total additional payment surplus. The first partial derivatives in the universal form are:

$$
\frac{\partial \mathrm{CF}(\overrightarrow{\Delta m})}{\partial \Delta m_{i}}=\frac{\partial I_{i j}^{\mathrm{cur}}\left(\Delta m_{i j}\right)}{\partial \Delta m_{i}}-\frac{\partial O_{i j}^{\mathrm{cur}}\left(\Delta m_{i j}\right)}{\partial \Delta m_{i}}+\frac{\partial S_{i j}^{\mathrm{cur}}\left(\Delta m_{i j}\right)}{\partial \Delta m_{i}}+\frac{\partial E^{\mathrm{cur}}(f(\overrightarrow{\Delta m}))}{\partial \Delta m_{i}}
$$




$$
\frac{\partial \mathrm{CF}(\overrightarrow{\Delta m})}{\partial \Delta m_{j}}=\frac{\partial I_{i j}^{\mathrm{cur}}\left(\Delta m_{i j}\right)}{\partial \Delta m_{j}}-\frac{\partial O_{i j}^{\mathrm{cur}}\left(\Delta m_{i j}\right)}{\partial \Delta m_{j}}+\frac{\partial S_{i j}^{\mathrm{cur}}\left(\Delta m_{i j}\right)}{\partial \Delta m_{j}}+\frac{\partial E^{\mathrm{cur}}(f(\overrightarrow{\Delta m}))}{\partial \Delta m_{j}}
$$

Based on the first partial derivatives the partial marginal solutions, conditions and characteristics of an internal solution can be obtained. For a detailed description on how to determine these values we refer the interested reader to Kamprath and Röglinger (2011).

As the target of this paper is to introduce a blueprint for the transformation of companies towards sustainability, the applied functions are not further specified. Each company, which aims at aligning ecological, social, and economic objectives and drawing economically useful conclusions in this context, has to customize the proposed functions. Furthermore, potentially existing synergies and rivalries between the dimensions of sustainability and between the corporate activities have to be further examined as they were not analyzed in detail in this model. Additionally, the individual actions to reach the economically optimal target have to be outlined. Altogether, the presented decision model allows identifying the economically optimal increase of the sustainability maturity level of each identified corporate activity and thus represents a first approach to quantify decisions regarding transformation towards sustainability.

\section{Operationalization of the approach}

As the real-world application of a model generally allows drawing interesting implications for its further operationalization, in the following we describe an example of how to manage sustainability projects in practice, applying our approach. We were able to accompany the instantiation of the Sustainability Maturity Cube and the application of our decision model in an in its branch leading and listed German middle-sized company. To outline how a specific company can transform towards sustainability, we first present the data collection process and then define the corporate activities and their current sustainability maturity levels. To test the robustness of our approach, we perform a sensitivity analysis based on these findings.

\subsection{Data collection}

There are various possibilities of how to acquire genuine values for the theoretically developed input parameters. Publicly available data, e.g., by the Federal Statistical Office, other public or scientific institutions or historic and current intra-corporate data (e.g., in a data warehouse) are viable sources. Also conducting studies or consultations of external experts (e.g., interview of stakeholders) allows defining the input parameters. Furthermore, for the specific sustainability context almost all of the frameworks introduced in Table 6 of the Appendix (e.g., the global reporting initiative, the environmental management systems) provide sustainability indicators 
that can offer guideline on how to determine the necessary input parameters of our decision model.

The regarded company has already been awarded for its customer focus and innovative business model and states, e.g., in its annual reports and on the company homepage that sustainability plays an important role for its success. Experts from different business areas of the company (amongst other IT, market management, and executive management) helped us to reflect on the approach and to collect data for the input parameters. Although the subject matter experts were willing to participate in the evaluation of the current status and the practices we were not able to cope with the complexity of the entire existing sustainability issues. We faced the following major challenges: Transforming the experiences with sustainability projects into functions is not straightforward and complex interrelations may need to be simplified. The same holds true for the synergies and rivalries between corporate activities and the dimensions of sustainability. Nevertheless, we gained valuable insights into the difficulties encountered during data collection and analysis regarding whether the decision model creates utility. To sum it up, with consulting internal experts of the regarded company we determined parts of the input parameters. Those input parameters, however, that could not directly be assessed in the interviews were estimated based on other publicly available data and the aforementioned scientific sustainability frameworks.

\subsection{Identification of sustainability actions and corresponding starting points}

In a first step, the so far only abstractly defined perspectives of the Sustainability Maturity Cube (Corporate Activities, Sustainability Maturity Levels) have to be substantiated. The company chooses Porter's value chain to structure the corporate activities (1st perspective), and the sustainability maturity model of Cagnin et al. (2011) whose sustainability maturity levels develop from ad hoc (1), planned in isolation (2), managed with no integration (3), excellence at corporate level (4), to high performance sustainability net (5) (2nd perspective). Hence, we have: $m_{i j}^{\min }=$ 1 and $m_{j i}^{\max }=5$.

For the instantiation of the Sustainability Maturity Cube, several more issues need to be considered: to analyze the current sustainability maturity level in the regarded company we had a look at corporate strategy and its operationalization: As maximum customer benefit is a main corporate goal, its products are designed to help its customers to operate in a sustainable manner. The interviews conducted allowed us to break this strategic goal down to the different dimensions of sustainability. The company is involved in the following sustainability actions and we were hence able to identify the following corresponding starting points:

- Regarding the ecological commitment, constant improvement of the products with a view to reducing the consumption of power, water and all resources that are involved in the use and production of the products is most important (starting point is corporate activity "operations" and ecological dimension).

- Social commitment is achieved by acting responsibly towards employees which means an appropriate work-life balance and direct participation of employees in 
the success of the company (starting point is corporate activity "outbound logistics" and social dimension).

- Further social commitment is achieved by actively supporting social and cultural activities in the region (starting point is corporate activity "infrastructure" and social dimension).

- Considering the economic dimension, the following findings were deduced from the interviews: for the regarded company sustainable and long-term economic activity is more important than achieving short-termed profits. This is reflected in a high customer satisfaction, which ultimately results in the continuous growth of sales and profits, and in a high employee satisfaction.

As the interviews revealed that the company did not yet focus on specifying the definite starting points regarding the dimensions of sustainability, the subject matter experts were asked for their indications of the sustainability maturity levels of the corporate activities. For each corporate activity, the questions considered not only the assessment of the current state of sustainability within the company (number of measures applied, evaluation of level of management involvement) but also its expected potential (number of measures approved or planned). The survey was conducted on a five-step Likert scale ( $1=$ low; $5=$ high), which allows to translate the answers into sustainability maturity levels. Considering the varying answers of the experts from different business areas, the aggregated current sustainability maturity levels of the corporate activities (weighted average over all answers from the experts) were defined as follows:

$$
\begin{aligned}
& C_{1}: \text { operations }\left(m_{1}^{\text {cur }}=1.00\right) \\
& C_{2}: \text { outbound logistics }\left(m_{2}^{\text {cur }}=1.00\right) \\
& C_{3}: \text { infrastructure }\left(m_{3}^{\text {cur }}=1.67\right)
\end{aligned}
$$

\subsection{Determination of the economically optimal increase of the sustainability maturity levels}

To derive the economic consequences, the investments, cash outflows, savings, and cash inflows have to be estimated according to the business cases the company had developed for single sustainability decisions. We assume that each component of the total additional payment surplus $\mathrm{CF}(\overrightarrow{\Delta m})$ is characterized by the previously proposed gradient, e.g., quadratic and root functions and hence we define exemplary functions. We further assume that investments, cash outflows of operational business and savings only depend on the aggregation function $g\left(\overrightarrow{\Delta m_{i}}\right)$ with $\overrightarrow{\Delta m}_{i}=$ $\left(\Delta m_{i 1}, \Delta m_{i 2}, \Delta m_{i 3}\right)^{T}$ and hence potential synergies or rivalries between the different dimensions of sustainability within one corporate activity are already considered. Additionally, the cash inflows depend on the total (company-wide, overall corporate activities) sustainability maturity level formalized by aggregation function $f(\overrightarrow{\Delta m})$ with $\overrightarrow{\Delta m}=\left(\overrightarrow{\Delta m}_{1}, \ldots, \overrightarrow{\Delta m_{n}}\right)^{T}$ which aggregates the total sustainability maturity level regarding the synergies and rivalries between different corporate activities. 
Table 2 Continuous functions based on $m_{i}^{\text {cur }}$

\begin{tabular}{lllll}
\hline$i$ & $\begin{array}{l}\text { Investment } \\
I_{i}^{\text {cur }}\left(g\left(\overrightarrow{\Delta m_{i}}\right)\right)\end{array}$ & $\begin{array}{l}\text { Cash outflows of operational } \\
\text { business } O_{i}^{\text {cur }}\left(g\left(\overrightarrow{\Delta m_{i}}\right)\right)\end{array}$ & Savings $S_{i}^{\text {cur }}\left(g\left(\overrightarrow{\Delta m_{i}}\right)\right)$ & $\begin{array}{l}\text { Cash inflow } \\
E^{\text {cur }}(f(\Delta m))\end{array}$ \\
\hline 1 & $9 \cdot \Delta \mathrm{m}_{1}^{2}+2 \cdot \Delta \mathrm{m}_{1}$ & $5 \cdot \Delta \mathrm{m}_{1}^{2}+4 \cdot \Delta \mathrm{m}_{1}$ & $7 \cdot \Delta \mathrm{m}_{1}^{0.5}$ & $185 \cdot \sqrt{(f(\overrightarrow{\Delta m}))}$ \\
2 & $7 \cdot \Delta \mathrm{m}_{2}^{2}+5 \cdot \Delta \mathrm{m}_{2}$ & $3 \cdot \Delta \mathrm{m}_{2}^{2}+7 \cdot \Delta \mathrm{m}_{2}$ & $10 \cdot \Delta \mathrm{m}_{2}^{0.5}$ \\
3 & $4 \cdot \Delta \mathrm{m}_{3}^{2}+8 \cdot \Delta \mathrm{m}_{3}$ & $2 \cdot \Delta \mathrm{m}_{3}^{2}+9 \cdot \Delta \mathrm{m}_{3}$ & $8 \cdot \Delta \mathrm{m}_{3}^{0.5}$ & \\
\hline
\end{tabular}

In the regarded company where we had already defined the current sustainability maturity levels of the corporate activities $C_{1}$ : operations $\left(m_{1}^{\text {cur }}=1.00\right), C_{2}$ : outbound logistics $\left(m_{2}^{\text {cur }}=1.00\right)$ and $C_{3}$ : infrastructure $\left(m_{3}^{\text {cur }}=1.67\right)$, the experts from different business areas helped us to determine the parameters of the components of the total additional payment surplus $\mathrm{CF}(\overrightarrow{\Delta m})$. We assume the functions as shown in Table 2.

The calculation of the optimal increase of the sustainability maturity level can be implemented, e.g., in Microsoft Excel. For the given company and the regarded circumstances the following results are achieved (rounded values): $\Delta m_{1}=0.40$, $\Delta m_{2}=0.66$ and $\Delta m_{3}=0.68$. The payment surplus is thus 16.88 TEUR. By investing 41.25 TEUR in total, cash inflows of 75.67 TEUR, cash outflows of operational business of 27.77 TEUR, and saving of 10.23 TEUR can be achieved. For the regarded company it is thus economically useful to aim at increasing all of the regarded maturity levels. Here, the biggest potential lies in the corporate activity "infrastructure" - even though this activity is already at a higher maturity level compared to the others.

\subsection{Analysis of the decision model behavior conducting a sensitivity analysis}

Acquiring reliable real-world data to profoundly examine the benefits of our theoretic approach is rather difficult in the multi-faceted context of sustainability. Furthermore, estimated parameter values and assumptions are generally subject to change and error (Pannell 1997). We therefore analyze the behavior of our decision model regarding sustainability decisions in detail by performing a sensitivity analysis. This is a common method from decision-making theory and aims on examining how sensitive a model's results are to changes in the input variables (Kim et al. 2009; Pannell 1997; Saltelli et al. 2008; Triantaphyllou and Sánchez 1997).

In the basic form of a sensitivity analysis, the value of a certain input parameter is varied within a specific range around the best guess value (see above) while keeping all other input parameters constant (Pannell 1997; Saltelli et al. 2008). In our analysis we change each input parameter by plus, respectively, $-10 \%$ compared to its original value estimated by the experts while keeping all other input parameters constant, and repeat this procedure with every input parameter of interest. In order to abstract from the effects that result from the different sizes of the input parameters, we complement the analysis by changing the input parameters in their 


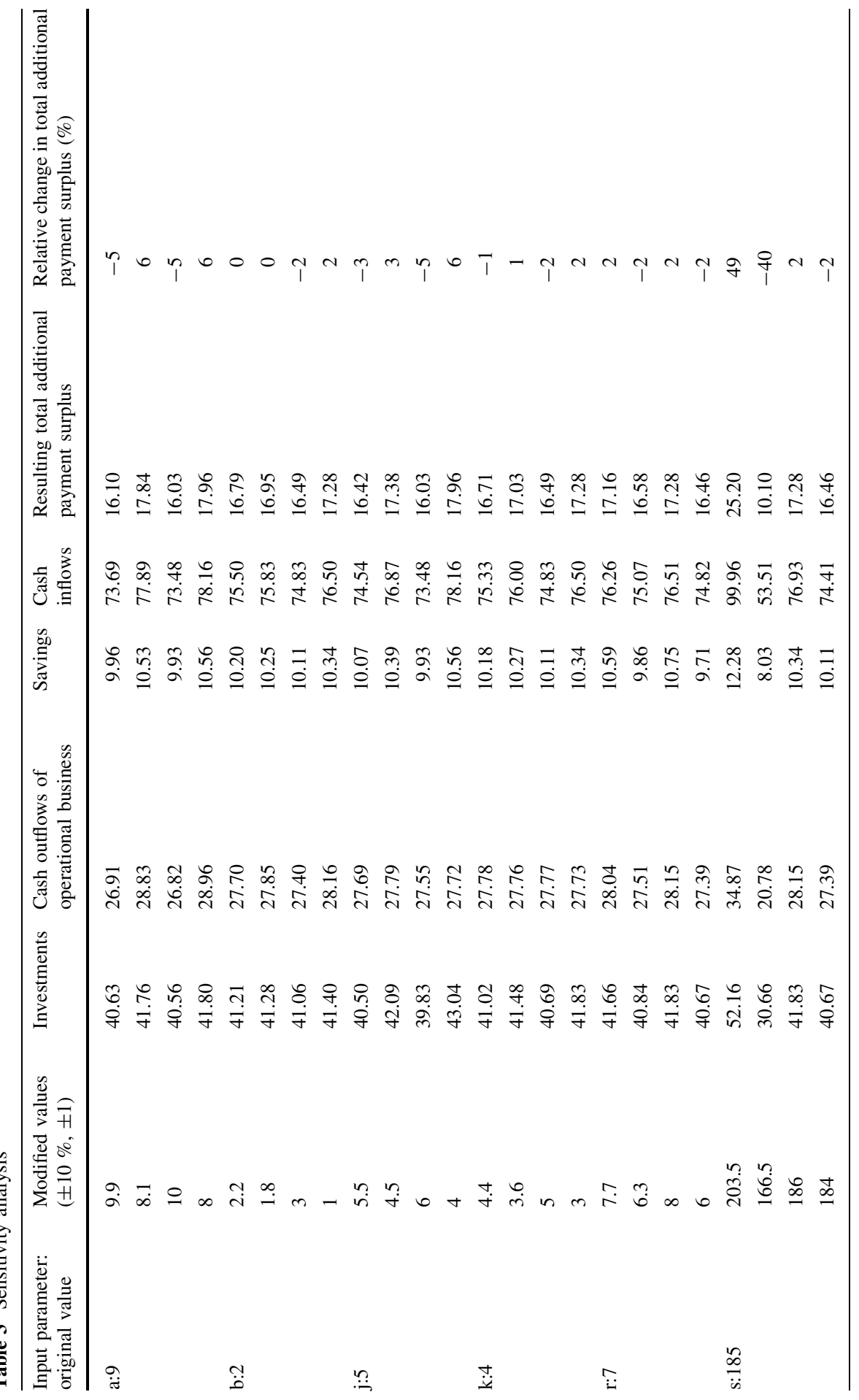


absolute size by plus, respectively, -1 . The major objectives thus are to test the robustness of the decision model's results regarding the parameterization of certain input values and to gain a deeper understanding about the relationships between input parameters and the outcome.

We show the results of the described sensitivity analysis for one exemplary corporate activity $\left(C_{1}\right.$ : operations). This restriction is legitimate as the behavior of all corporate activities resembles one another due to the same nature of the underlying functions. The results are presented in Table 3. In the first column, we listed the initial values for the input parameters as estimated by the experts (see also Table 2, first line for corporate activity $C_{1}$ ). The subsequent columns contain the changed results according to the variation of the input parameters for the sum over all corporate activities for each of the following components: investments (column 3 ), cash outflows of operational business (column 4), savings (column 5) and cash inflows (column 6) followed by the resulting total additional payment surplus (column 7), and the respective relative change in the total additional payment surplus (column 8). Each row thereby consists of two sub-rows. The upper sub-row contains the results when the parameter value is increased and decreased by $10 \%$ relative to the initial value (column 2). The lower sub-row contains the results of an absolute parameter variation of plus and minus 1 (column 2).

The conducted analysis allows us to draw the following conclusions:

- The direction of the changes of the total additional payment surplus is as expected from an analytical point of view: an increase (decrease) of the cash outflows leads to a decrease (increase) of the total additional payment surplus and vice versa for the cash inflows. Here, increased (decreased) savings or increased (decreased) cash inflows lead to an increased (decreased) total additional payment surplus.

- Furthermore, the result of our decision model is quite robust for our real-world example: The relative change in the total additional payment surplus is generally small and considerably lower than the $10 \%$ variation of the respective input parameter except for the case of the expected cash inflows. Here, the variation of $s$ by $\pm 10 \%$ results in a $49 \%(-40 \%)$ increase (decrease) of the total additional payment surplus. This can be explained by the high absolute value of the input parameter $s$ compared to all other input parameters. One reason might be the fact, that in contrast to all other input parameters, the cash inflows are the only component in our example that depends on the aggregated total sustainability maturity level (aggregation function $f(\overrightarrow{\Delta m})$ ) over all corporate activities, whereas the other input parameters only contain the effects of just one corporate activity (aggregation function $g\left(\overrightarrow{\Delta m_{i}}\right)$ ). Another reason to justify this comparably high value of the cash inflows is the fact that the customer equity which is the main building block of this cash flow component is a futureoriented figure that includes long-term effects.

In order to abstract from this relative size effect, we furthermore examined the absolute variation of the input parameters (the lower two sub-rows for each input parameter in Table 3). The same absolute variation of \pm 1 for all input parameters 
results in a similar low variation of the total additional payment surplus (column 7 and 8). This also holds true for the variation of the input parameter $s$ (variation of the total additional payment surplus of $+2 \% /-2 \%$ ).

Hence, when estimating the cash inflows, special attention has to be paid to the consequences of misestimating long-termed effects like customer-related issues, as these can be higher than rather short-termed ones. Moreover, as the cash inflows depend on the aggregated function over all corporate activities, these can be higher than the other components that only focus on single corporate activities and consequently have a considerable stronger effect on the model results.

In the previous analysis we only focused on the variation of the input parameters of one corporate activity ( $C_{1}$ operations) within the three examined corporate activities. As the same experts were asked to assess the current state of sustainability for all corporate activities, this restriction on one corporate activity is legitimate. Even more, the direction of effects on the model output remains the same independently of the considered corporate activity due to the equal nature of their underlying functions. However, when estimating the input parameters it is possible that the experts over- or underestimate not just one, but for example the same input parameter for all corporate activities at the same time, which consequently leads to stronger effects regarding the change of the output. Moreover, in order to consider that humans in dependence of their attitude towards risk tend to be rather optimistic or pessimistic regarding future cash flows, we applied one optimistic and one pessimistic scenario besides the presented base case scenario to further complement the analysis. We deduce the values for the optimistic and pessimistic scenario as follows: in the optimistic case, we expect the experts to underestimate the investments and cash outflows of operational business while overestimating the cash inflows and savings at the same time by $10 \%$ each for all three examined corporate activities. For the pessimistic case, we expect the experts to overestimate the investments and cash outflows of operational business while underestimating the cash inflows and savings by $10 \%$ each for all three examined corporate activities. Table 4 summarizes the results of this scenario analysis.

We can see that the relative change in the total additional payment surplus is quite substantial $(+117 \%$ and $-69 \%)$. This can be explained by the fact that compared to the analysis presented above where we focused on just one input parameter at a time, now all eighteen input parameters are misestimated by $10 \%$ each at the same time. In the pessimistic scenario, the total additional payment surplus decreases only by $69 \%$, which is quite low compared to the increase of $117 \%$ in the optimistic case. We can thus see that in our current case, a pessimistic estimation of cash in- and outflows leads to a lower change of the total additional payment surplus than an overly optimistic estimation of the respective input parameters does. When taking into account other current sustainability maturity levels for the corporate activities other results may be obtained and other conclusions can be drawn. This can be explained by the following: Depending on the gradient of the convex cash outflow and concave cash inflow functions and the respective starting point on the functions (i.e., current sustainability maturity levels) the same relative change of the input parameters for cash in- and outflows can lead to different results regarding the strength of the change on the output. 


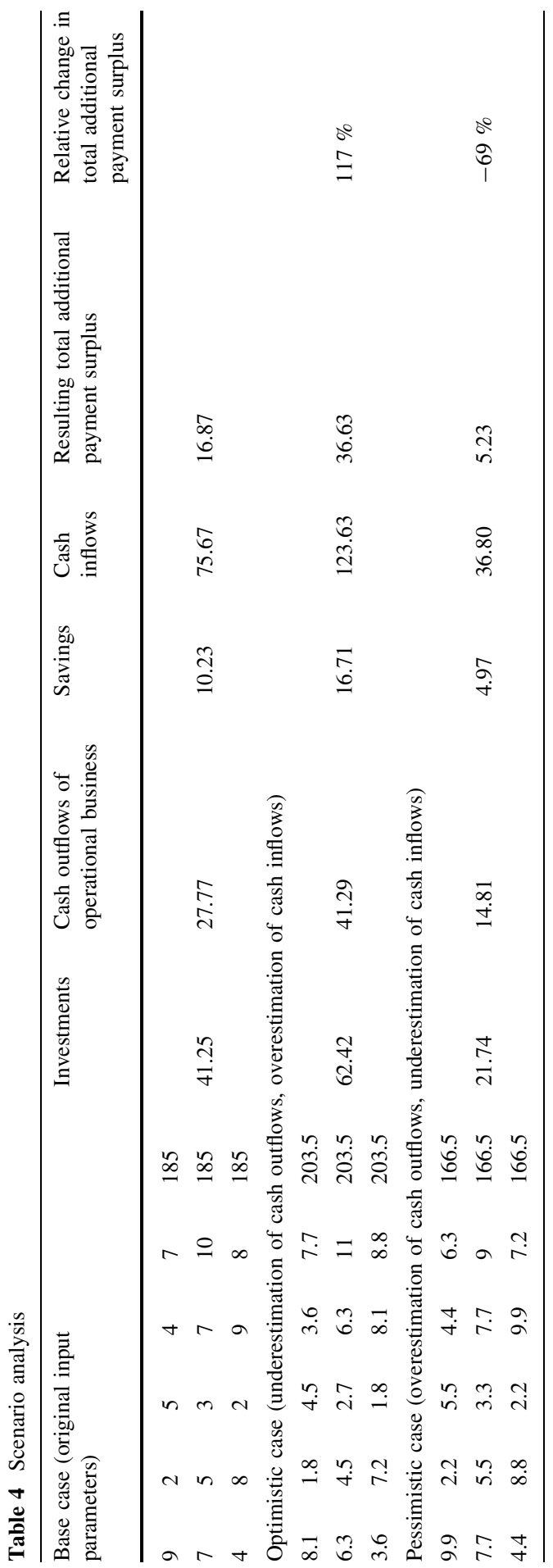


In the regarded case, the base case scenario is characterized by the fact that it is economically useful to aim at increasing all of the regarded maturity levels (i.e., current maturity levels located on the left side of the optimum). Hence, the underestimation of the convex cash outflows (leading to a lower gradient of the curve) and the overestimation of the concave cash inflows (also leading to a lower gradient of the curve) lead to a higher value of the total additional payment surplus in the optimum (optimistic case). In contrast, in the pessimistic case, both gradients of the functions increase, causing that the optimum for the estimated parameter values is reached with a lower increase in maturity levels than in the optimistic case.

The results of the presented analysis can build the basis for the transformation towards sustainability in the regarded company. Altogether, the proposed Sustainability Maturity Cube as a blueprint, as well as the adapted decision model of Kamprath and Röglinger (2011) created utility for the subject matter experts as they provided them with recommendations and means for further analysis (e.g., careful estimations, short-termed vs long-termed effects, effects of different absolute sizes of input parameters). They also helped to systematize the decision processes. The presented approach thus allows aligning ecological, social, and economic objectives and drawing economically reasonable conclusions in this context by determining the optimal increase of the sustainability maturity level.

\section{Contribution, limitations, and conclusion}

In order to maintain our current style of life, we would need the equivalent of two of our today's planets by 2030 (Buhl and Jetter 2009). Statements like this and the knowledge of scarce resources as well as the existence of more and more sensible customers (for example LOHAS) emphasize the necessity to integrate sustainable behavior into individual and corporate activities and decisions. Although it bears great potential for economic improvement, still little research exists in the field of the comprehensive concept of sustainability and how companies should engage in sustainability transformations.

With the presented Sustainability Maturity Cube as a blueprint and the decision model at hand, we contribute to theory and practice: it was our objective to integrate ecological, social, and economic objectives into corporate decisions. We first showed how organizations can structure the field of action, and suggested possible starting points within corporate processes where to implement sustainability actions (via analyzing the entire business system following Porter's value chain model) for all three dimensions of sustainability. Since implementing sustainability is characterized by continuous development, we adapted the basic idea of stages of 
development and maturity to sustainability context, in order to provide a possibility to describe the respective sequence of levels that form an anticipated path from an initial state to maturity. The resulting Sustainability Maturity Cube is a blueprint that is based on acknowledged scientific concepts to support the systematic improvement of sustainability management by considering certain corporate activities, the three dimensions of sustainability, and the corresponding stages of development (research question 1). Being a blueprint, it can be instantiated and hence provides the basis for developing concrete sustainability maturity models.

The second contribution is the proposed decision model that allows identifying the economically optimal increase of the sustainability maturity level of each identified corporate activity and each dimension of sustainability, respectively (research question 2). Our approach thereby represents a first step to align decisions regarding the transformation towards sustainability with the paradigm of valuebased management, taking into account the ambiguous role of the economic dimension in business context. Finally, the instantiation of the blueprint and the applicability of the decision model were illustrated by the example of a German medium-sized company and tested for its robustness, performing a sensitivity analysis. Overall, the approach delivers a contribution to theoretical and practical knowledge in the multidisciplinary research field of transformation towards sustainability and, in parallel, offers a basis or starting point for further research.

Besides the previously highlighted benefits, our approach offers scope for discussion and implicates limitations:

- The difficulties regarding a clear definition, understanding and operationalization of (corporate) sustainability show that sustainable development is a complex and multidimensional issue. Hence, a clear and unambiguous managerial advice cannot be given. The understanding of corporate sustainability in this paper is based on the belief that the economic perspective is of particular importance in a business context and can be seen as ambiguous. On the one hand, it is one of the three sustainability dimensions, but at the same time - in conformity with the paradigm of value-based management emerges as an additional organizational incentive when engaging in sustainability transformation. This explains the understanding of corporate sustainability for this work; however, future research needs to further dispute this controversy.

- The empirical evidence of whether all customers care about sustainability issues and express their concerns through purchasing behavior and thus price sensitivity is debatable. Even those customers, who say they care about sustainability, do not necessarily reflect their attitude in their purchasing habit (Bonini and Oppenheim 2008; Bellows et al. 2008; Fisher 1993; Pickett-Baker and Ozaki 2008). As a consequence, sustainable practices may directly and negatively affect profitability, and organizations may refrain from diving into adopting sustainable practices. 
- Determining the concrete monetary values of the consequences of sustainability actions is not straightforward as there does not always exist a metric that can be estimated: in some cases one of the numerous frameworks of sustainability assessment can provide assistance in determining such sustainability metrics but this may not be always reliable. Hence, some of the values depend on the estimation of subject matter experts. An objectification is desirable, but would require further research.

- There are several issues that have to be considered when instantiating a concrete sustainability maturity model, such as the determination of current and targeted sustainability maturity levels, the formulation of concrete development paths from initial to desired maturity levels, confounding effects (e.g., when implementing several actions at the same time) and situations when it makes sense to invest in a particular action or not. We addressed some of these aspects in the operationalization of the approach; however, further research needs to focus on guidelines for the operationalization of the Sustainability Maturity Cube.

- Future research should also focus on a more extensive evaluation of the proposed approach as we only used an illustrative case for the operationalization. Even though this case allows for an initial instantiation of the Sustainability Maturity Cube, the findings are not aimed at making generalizations.

These limitations provide room for further research in this area. Nevertheless, our approach delivers insights in the assessment of sustainability and may serve as a first step towards integrating sustainability into organizations and corporate decisionmaking.

Open Access This article is distributed under the terms of the Creative Commons Attribution License which permits any use, distribution, and reproduction in any medium, provided the original author(s) and the source are credited.

\section{Appendix}

See Tables 5 and 6. 


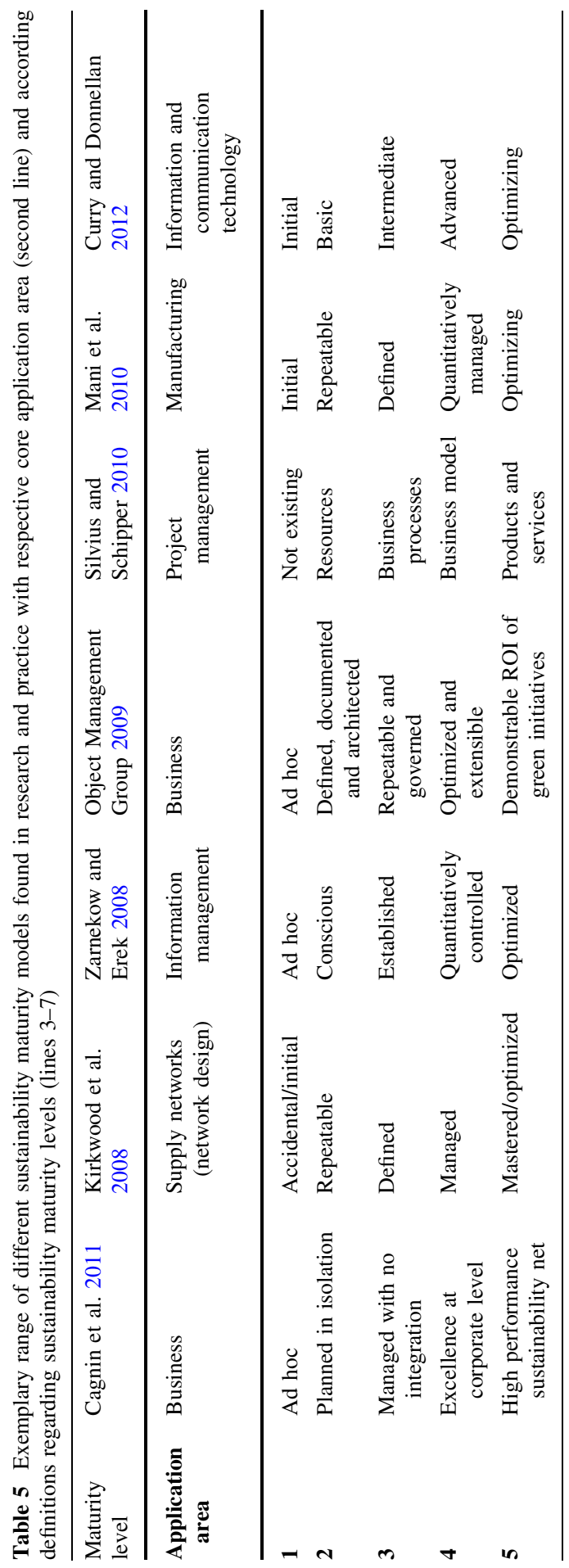




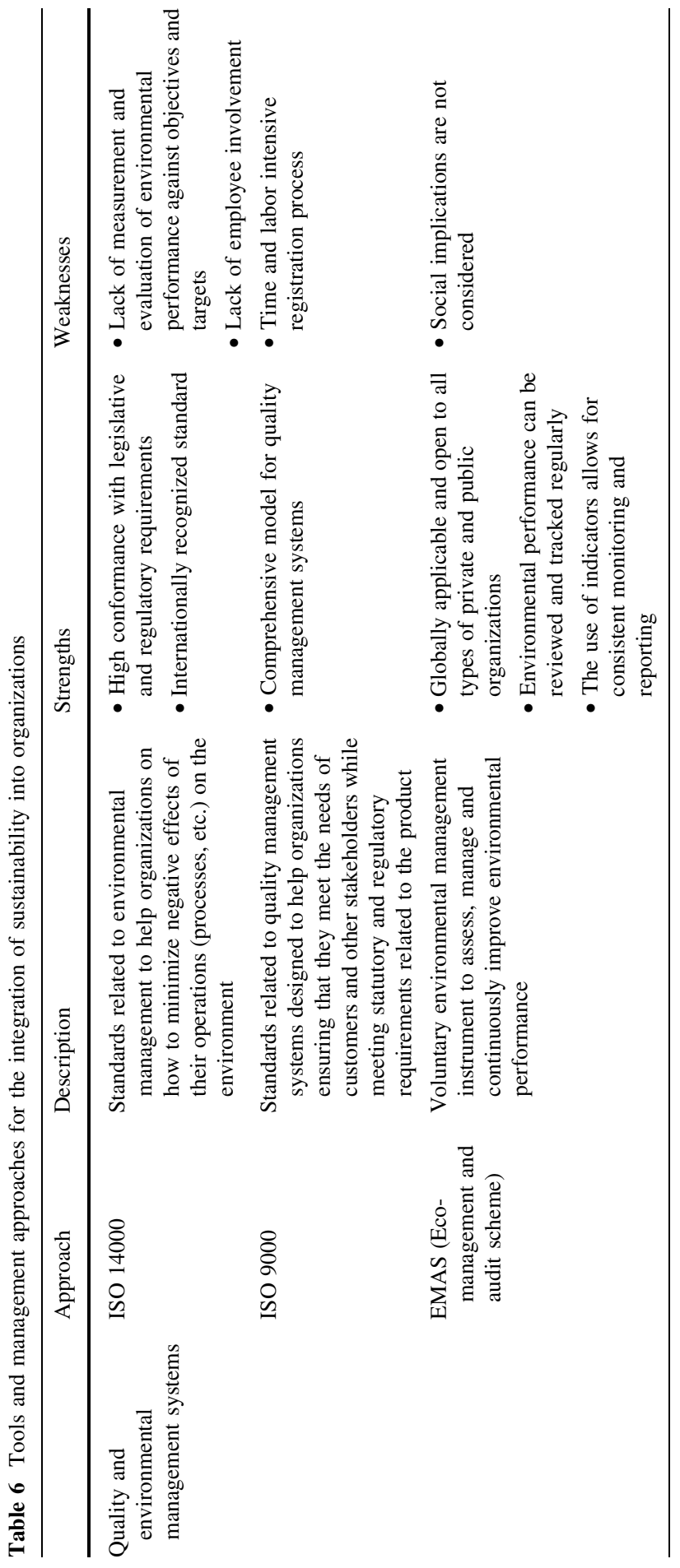




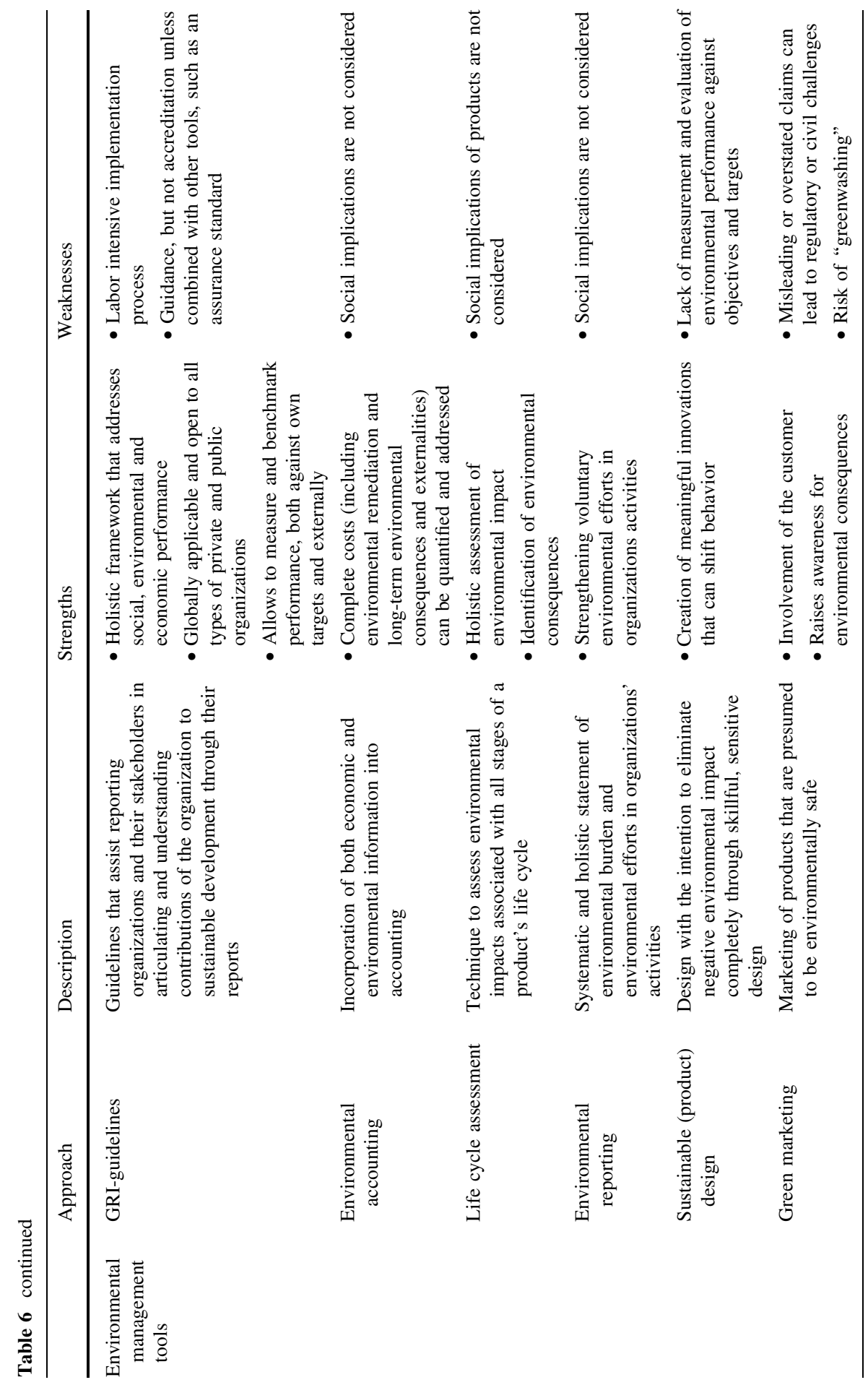




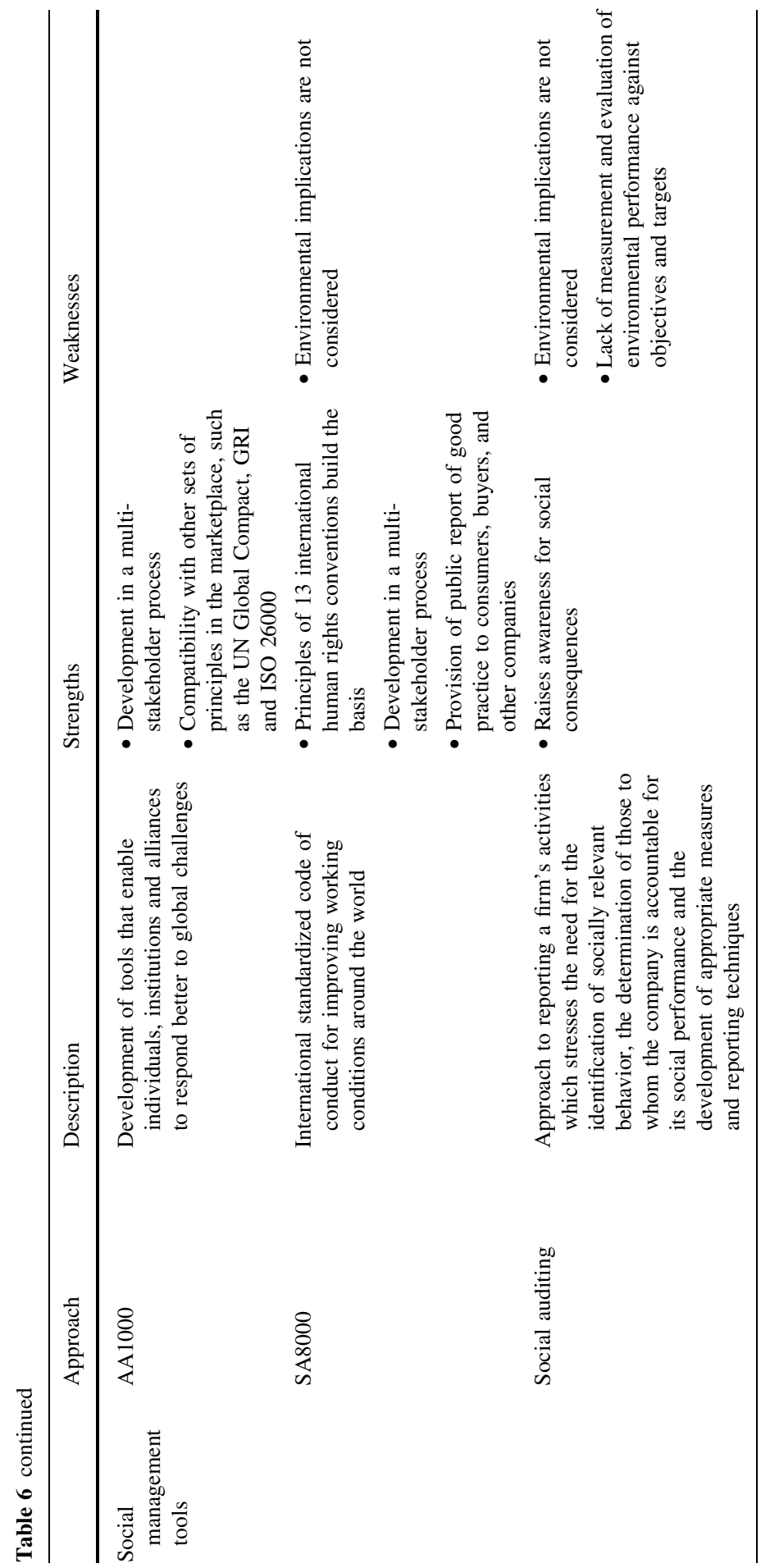




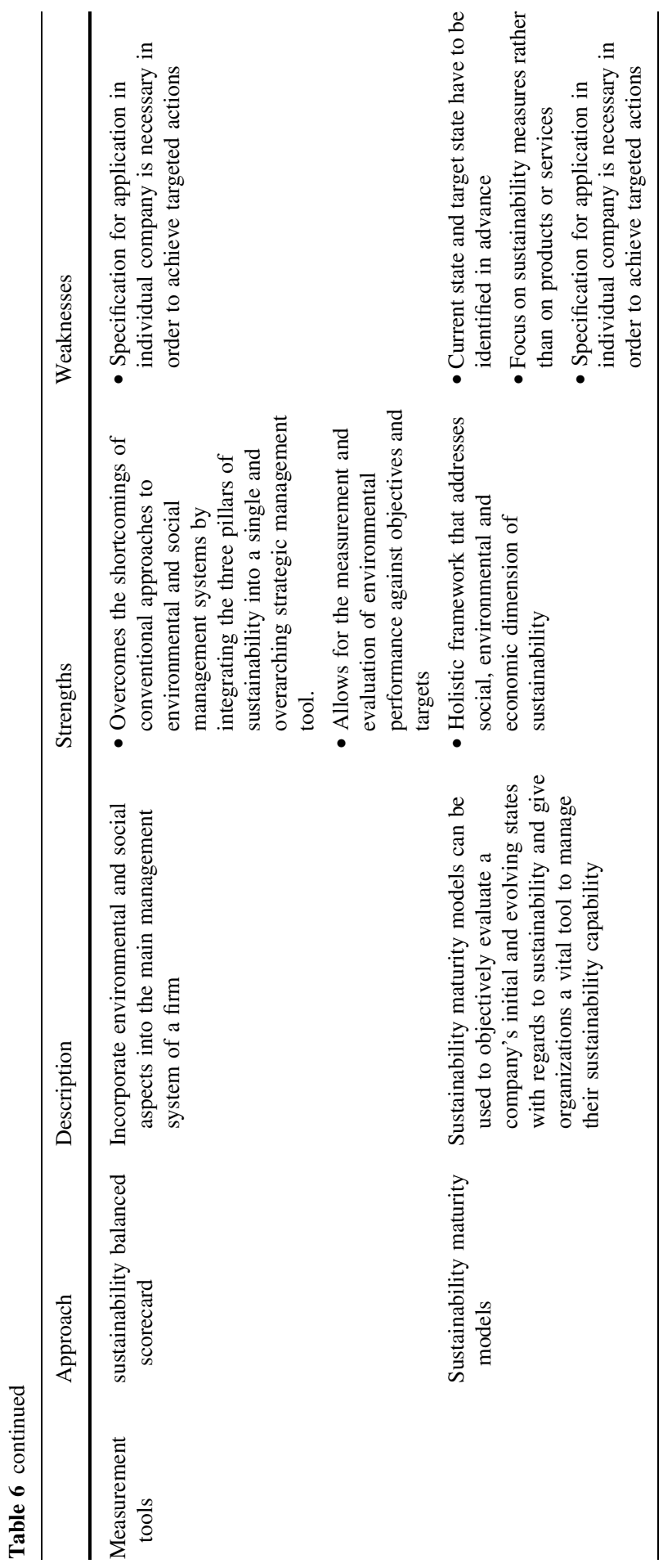




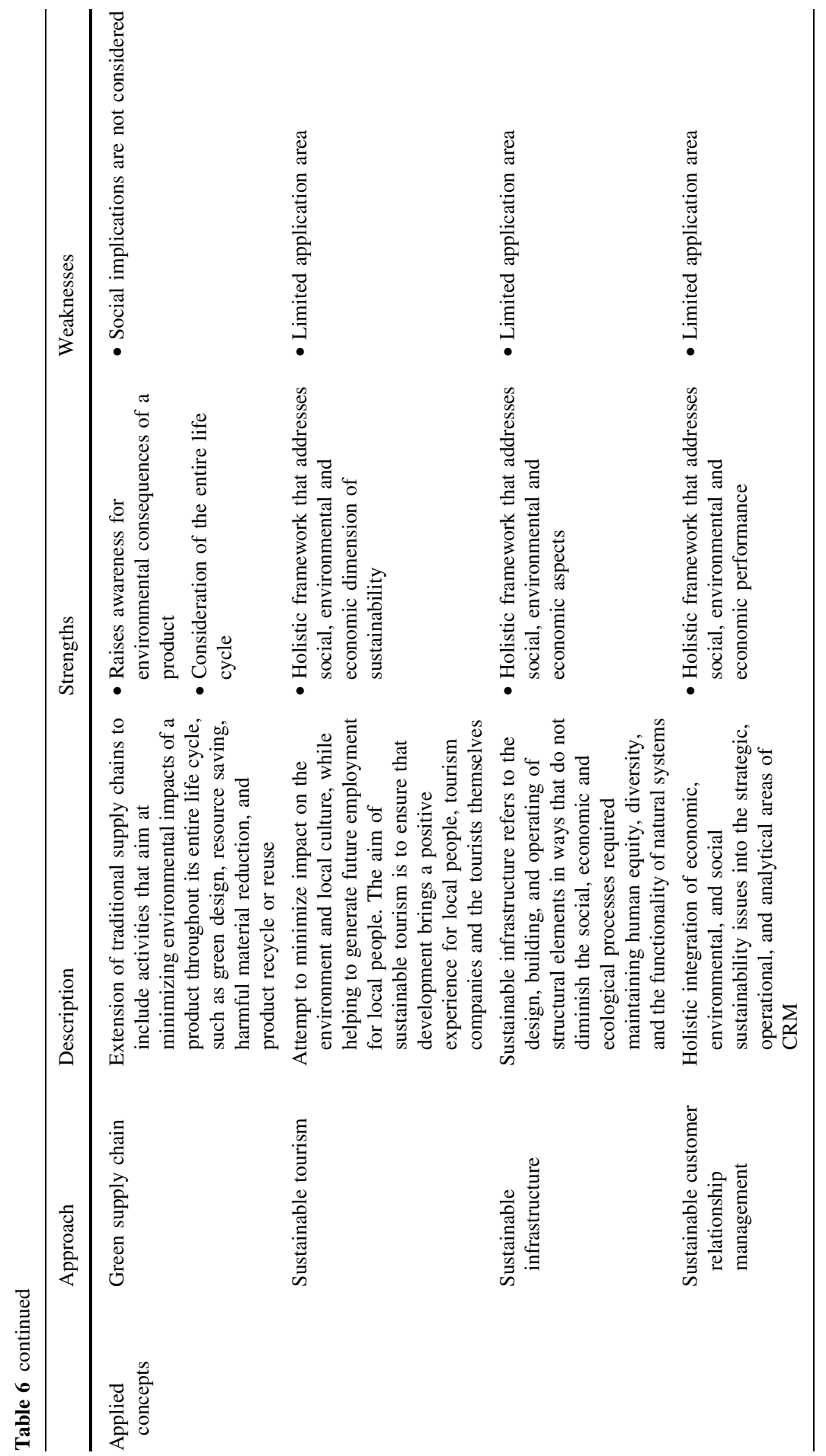




\section{References}

AIChE. 2004. Center for waste reduction technologies (CWRT), focus area sustainability metrics. http:// www.aiche.org/cwrt/pdf/BaselineMetrics.pdf. (Access date: 2013-07-15).

Arnold, Hugh J., and Daniel C. Feldman. 1982. A multivariate analysis of the determinants of job turnover. Journal of Applied Psychology 67(3): 350-360.

Atkinson, Giles. 2000. Measuring corporate sustainability. Journal of Environmental Planning and Management 43(2): 235-252.

Bansal, Pratima, and Kemdall Roth. 2000. Why companies go green: a model of ecological responsiveness. Academy of Management Journal 43(4): 717-736.

Bansal, Pratima, and W. Bogner. 2002. Deciding on ISO 14001: economics, institutions, and context. Long Range Planning 35(3): 269-290.

Baumgartner, Ruppert J. 2005. Sustainable business management: Grundlagen, Strategien und Instrumente einer nachhaltigen Unternehmensführung. In Wertsteigerung durch Nachhaltigkeit, ed. Ruppert J. Baumgartner, 51-72. Rainer Hampp: Munich.

Baumgartner, Ruppert J., and Daniela Ebner. 2010. Corporate sustainability strategies: sustainability profiles and maturity levels. Sustainable Development Sustainable Development 18(2): 76-89.

Becker, Jörg, Ralf Knackstedt, and Jens Pöppelbuß. 2009. Developing maturity models for IT management-a procedure model and its application. Business and Information Systems Engineering 1(3): 213-222.

Bellows, Anne C., Benjamin Onyango, Adam Diamond, and William K. Hallman. 2008. Understanding consumer interest in organics: production values vs. purchasing behavior. Journal of Agricultural and Food Industrial Organization 6(1): 1-31.

Boehm, Barry W., Chris Abts, Brown A. Windsor, Sunita Chulani, Bredfort K. Clark, Ellis Horowitz, Ray Madachy, Donald Reifer, and Bert Steece. 2000. Software cost estimation with COCOMO II. NJ: Prentice-Hall.

Bonini, Shella M.J., and Oppenheim, Jeremy M. 2008. Helping 'green' products grow. McKinsey Quarterly. http://www.mckinsey.it/idee/mckinsey_quarterly/helping-green-products-grow.view. (Access date: 2013-08-11).

Brown, Halina Szejnwald, Martin de Jong, and Teodrina Lessidrenska. 2009. The rise of the global reporting initiative: a case of institutional entrepreneurship. Environmental Politics 18(2): 182-200.

Buhl, Hans U., and Martin Jetter. 2009. BISE's responsibility for our planet. Business and Information Systems Engineering 1(4): 273-276.

Cagnin, Christiano H., Denis Loveridge, and Jeff Butler. 2011. Business sustainability maturity model, 13-14. Corporate responsibility research conference, United Kingdom: University of Leeds.

Ciegis, Remigijus, Jolita Ramanauskiene, and Grazina Startiene. 2009. Theoretical reasoning of the use of Indicators and indices for sustainable development assessment. Engineering Economics 3: 33-40.

Clarkson, Max B.E. 1995. A stakeholder framework for analyzing and evaluating corporate social performance. The Academy of Management Review 20(1): 92-117.

Curry, Edward, and Brian Donnellan. 2012. Understanding the maturity of sustainable ICT. In Green business process MANAGEMENT-towards the sustainable enterprise, ed. Jan vom Brocke, Stefan Seidel, and Jan Recker, 203-216. Berlin: Springer.

de Bruin, Tonia, Freeze, Ronald, Kulkarni, Uday, and Rosemann, Michael. 2005. Understanding the main phases of developing a maturity assessment model. In Proceedings of the 16th Australasian Conference on Information Systems, eds. Campbell B, Underwood J, Bunker D, 1-10. Sydney.

Elkington, John. 1997. Cannibals with forks: the triple bottom line of 21st century business. Oxford: Capstone.

Epstein, Marc J. 2008. Making sustainability work: best practices in managing and measuring social and environmental impacts. Greenleaf: Sheffield.

Ferguson, Gael, Andrew Dakers, and Ian Gunn. 2003. Sustainable waste management: a hand book for smaller communities, vol. 477. Ministry for the Environment: New Zealand.

Figge, Frank, and Tobias Hahn. 2004a. Sustainable value added-measuring corporate contributions to sustainability beyond eco-efficiency. Ecological Economics 48(2): 173-187.

Figge, Frank, and Tobias Hahn. 2004b. Value-oriented impact assessment: the economics of a new approach to impact assessment. Journal of Environmental Planning and Management 47(6): 921-941. 
Figge, Frank, Hahn, Tobias, Schaltegger, Stefan, and Wagner, Marcus (2001): The Sustainability Balanced Scorecard - a tool for value-oriented sustainability management in strategy-focused organisations. Conference Proceedings of the 2001 Eco-Management and Auditing Conference. ERP Environment: Shipley, 83 - 90.

Figge, Frank, Tobias Hahn, Stefan Schaltegger, and Marcus Wagner. 2002. The sustainability balanced scorecard-linking sustainability management to business strategy. Business Strategy and Environment 11: 269-284.

Fisher, Robert J. 1993. Social desirability bias and the validity of indirect questioning. Journal of Consumer Research 20(2): 303-315.

Freeman, R.Edward. 1984. Strategic management: a stakeholder approach. Boston: Pitman.

Global reporting initiative (2013): G4 sustainability reporting guidelines. https://www.globalreporting. org/reporting/g4/Pages/default.aspx. (Access date:2014-02-24).

Grande, Carlos .2007. Ethical consumption makes mark on branding, BusinessWeek, September 5/12:7880.

Goodland, Robefi. 1995. The Concept of environmental sustainability. Annual Review of Ecology and Systematics 26(1): 1-24.

Gupta, Sunil, and Donald R. Lehmann. 2003. Customers as assets. Journal of Interactive Marketing 17(1): 9-24.

Hahn, Tobias, and Mandy Scheermesser. 2006. Approaches to corporate sustainability among German companies. Corporate Social and Responsible Environmental Management 13(3): 150-165.

Hardtke, Arndt, and Marco Prehn. 2001. Perspektiven der Nachhaltigkeit. Wiesbaden: Gabler.

Heijungs, Reinout, and Jeroen B. Guinée. 1992. Environmental life cycle assessment of products. Centrum voor Milieukunde: Leiden.

Hiddleberger, Eric J., and Jeffery Hittner. 2009. Leading a sustainable enterprise-leveraging insight and information to act. Somers: IBM Institute for Business Value. IBM Global Services.

Huizing, Ard, and H.Carel Dekker. 1992. Helping to pull our planet out of the red: an environmental report of BSO/origin. Accounting, Organizations and Society 17(5): 449-458.

Iversen, Jakob, Peter A. Nielsen, and Jacob Norbjerg. 1999. Situated assessment of problems in software development. The DATA BASE for Advances, Information Systems 30(2): 66-81.

Kamprath, Nora, and Röglinger, Maximilian (2011): Ökonomische Planung von Prozessverbesserungsmaßnahmen-Ein modelltheoretischer Ansatz auf Grundlage CMMI-basierter Prozessreifegradmodelle, in: Bernstein A. and Schwabe G. (eds.): Proceedings of the 10th International Conference on Wirtschaftsinformatik, Zurich, 109-118.

Kaptein, Muel, and Johan Wempe. 2001. Sustainability management. Balancing conflicting economic, environmental and social corporate responsibilities. Journal of Corporate Citizenship 1(2): 91-106.

Kastenholz, Hans G., Karl-Heinz Erdmann, and Manfred Wolff. 1996. Nachhaltige Entwicklung. Zukunftschancen für Mensch und Umwelt. Berlin: Springer.

Kazanjian, Robert K., and Robert Drazin. 1989. An empirical test of a stage of growth progression model. Management Science 35(12): 1489-1503.

Kim, K., Lim, D., Park, H., and Kim, T. (2009) :A Sensitivity Analysis on the Impact of Uncertanties of the Supply and Demand of a Workforce on a Recruiting Strategy in an IT Service Company Proceedings of Americas conference on information systems: 1006-1012.

Kirkwood, David A., Alinaghian, Leila S., and Srai, Jagjit S. 2008. A maturity model for the strategic design of sustainable supply networks, IAS Working Paper. http://www.industrystudies.pitt.edu/ pittsburgh11/documents/Papers/PDF\%20Papers/3-2\%20Kirkwood.pdf. (Access Date: 2012-10-02).

Kiron, David, Nina Kruschwitz, Haanaes Knut, and Ingrid von Streng Velken. 2012. Sustainability nears a tipping point. MIT Sloan Management Review 53(2): 69-74.

Koplin, Julia. 2006. Nachhaltigkeit im Beschaffungsmanagement-Ein Konzept zur Integration von Umwelt- und Sozialstandards. Wiesbaden: Deutscher Universitäts-Verlag.

Krafft, Manfred. 1999. Der Kunde im Fokus: Kundennähe, Kundenzufriedenheit, Kundenbindung- und Kundenwert? Die Betriebswirtschaft 59: 511-530.

Krajnc, Damjan, and Peter Glavic. 2009. How to compare companies on relevant dimensions of sustainability. Ecological Economics 55(4): 551-563.

Lowe, Ian. 1998. Producing a better world: theory, education, and consulting. The American Behavioral Scientist 42(3): 531-538.

Mani, Mahesh, Lyons, Kevin, and Sriram, Ram. 2010. Towards the development of a sustainability manufacturing maturity model. In Proceedings from the IMS Summer School on Sustainable Manufacturing, 311-221. 
Matzler, Kurt. 2000. Customer value management. Die Unternehmung 54(4): 289-308.

Object Management Group und Green Computing Impact Organization. 2009. Green business maturity model. http://www.omg.org/news/meetings/tc/dc/special-events/GCIO/Green_Business_Maturity_ Model_GBMM_Overview.pdf. (Access date: 2012-09-27).

OECD. 2011. OECD guidelines for multinational enterprises. OECD Publishing.

Osterwalder, Alexander, and Yves Pigneur. 2002. An ebusiness model ontology for modeling eBusiness. In Proceedings of 15th Bled Electronic Commerce Conference - eReality: Constructing the eEconomy, ed. C. Loebbecke, R.T. Wigard, J. Gricar, A. Pucihara, and G. Lenart, 75-91. Slovenia: Bled.

Paulk, Marc C., Bill Curtis, Mary.Beth Chrissis, and Charles V. Weber. 1993. Capability maturity model, version 1.1. IEEE Software 10(4): 18-27.

Pannell, David J. 1997. Sensitivity analysis of normative economic models: theoretical framework and practical strategies. Agricultural Economics 2(16): 139-152.

Pickett-Baker, Josephine, and Ritsuko Ozaki. 2008. Pro-environmental products: marketing influence on consumer purchase decision. Journal of Consumer Marketing 25(5): 281-293.

Porter, Michael E. 1985. Competitive advantage: creating and sustaining superior performance. New York: Free Press.

Porter, Michael E., and Mark R. Kramer. 2006. Strategy and Society. The Link between Competitive Advantage and Corporate Social Responsibility, Harvard Business Review 84(12): 78-92.

Power, Anne. 2008. Does demolition or refurbishment of old and inefficient homes help to increase our environmental, social and economic viability? Energy Policy 36(12): 4487-4501.

Prakash, Aseem. 2001. Why do firms adopt 'beyond compliance' environmental policies? Business Strategy and the Environment 10(5): 286-299.

Prananto, Adi, Mckay, Judy, and Marshall, Peter (2003): A Study of the Progression of E-Business Maturity in Australian SMEs: Some Evidence of the Applicability of the Stages of Growth for E-Business Model, in; M. Hillier, D. Falconer, J. Hanisch, and S. Norrocks (eds.): Proceedings of the 7th Pacific Asia Conference on Information Systems, Adelaide, 68-80.

Ray, Paul H., and Sherry Ruth Anderson. 2000. The cultural creatives-how 50 million people are changing the world. New York: Three Rivers Press.

Robinson, Herbert S., Chimay J. Anumba, Patricia M. Carrillo, and Ahmid M. Al-Ghassani. 2004. STEPS: a Knowledge management maturity roadmap for corporate sustainability. Business Process Management Journal 12(6): 793-808.

Rosemann, Michael, and de Bruin, Tonia. 2005. Towards a business process management maturity model. In Proceedings of the 13th European Conference on Information Systems, eds. D. Bartmann, F. Rajola, J. Kallinikos, D.E. Avison, R. Winter, P. Ein-Dor, J. Becker, F. Bodendorf, and C. Weinhardt 25-35. Regensburg.

Rudolf-Sipötz, Elisabeth. 2001. Kundenwert: Konzeption-Determinanten-management. Thexis: St. Gallen.

Ruhwinkel, Max. 2013. Nachhaltigkeit im customer relationship management. Hamburg: Verlag Dr. Kovac.

Rummler, Geary A., and Alan P. Brache. 1990. Improving performance. San Francisco: Oxford.

Saltelli, A., Marco Ratto, Terry Andres, Francesca Campolongo, Jessica Cariboni, Debora Gatelli, Michaela Saisana, and Stefano Tarantola. 2008. Global Sensitivity Analysis. Hoboken: John Wiley \& Sons.

Salzmann, Oliver, Aileen Ionescu-Somers, and Ulrich Steger. 2005. The business case for corporate sustainability: literature review and research options. European Management Journal 23(1): 27-36.

Sanchez, Ron, and Aimé Heene. 2003. The new strategic management: organization, competition, and competence. Hoboken: John Wiley \& Sons.

Schaltegger, Stefan, Herzig, Christian, Kleiber, Oliver, and Müller. 2002. Sustainability Management in Business Enterprises. Concepts and Instruments for Sustainable Organisation Development, Bundesumweltministerium (BMU) und Bundesverband der Deutschen Industrie (BDI). Berlin.

Schaltegger, Stefan, and Müller, Martin. 2008. CSR zwischen unternehmerischer Vergangenheitsbewältigung und Zukunftsgestaltung. In Corporate Social Responsibility. Trend oder Modeerscheinung? oekom research, eds. Müller Martin, and Schaltegger Stefan 17-35. München.

Schmidt, Nils-Holger, Schmidtchen, Timo, Erek, Koray, Kolbe, Lutz M., and Zarnekow, Rüdiger. 2010. Influence of green IT on consumers' buying behavior of personal computers: implications from a conjoint analysis. In Proceedings of the 18th European Conference on Information System, eds. P.M. Alexander, M. Turpin, and J. P. van Deventer, 1-10. Pretoria. 
Seidel, Stefan, Recker, Jan C., Pimmer, Christoph, vom Brocke, Jan. 2010. Enablers and barriers to the organizational adoption of sustainable business practices. In Proceeding of the 16th Americas conference on information systems: sustainable IT collaboration around the globe, 1-10. Lima.

Silvius, Gilbert A.J., and Schipper, Ron. 2010. A maturity model for integrating sustainability in projects and project management. In 24th World Congress of the International Project Management Association (IPMA). Istanbul.

Software Engineering Institute. 2010. CMMI for development, version 1.3. http://www.sei.cmu.edu/ reports/10tr033.pdf. (Access date: 2012-07-29).

Triantaphyllou, Evangelos, and Alfonso Sánchez. 1997. A sensitivity analysis approach for some deterministic multi-criteria decision-making methods. Decision Sciences 1(28): 151-194.

United Nations Global Compact. 1999. The ten principles. http://www.unglobalcompact.org/ AboutTheGC/TheTenPrinciples/index.html. (Access date:2014-02-01).

van den Ven, Andrew H., and Marshall Scott Poole. 1995. Explaining development and change in organizations. Academy of Management Review 20(3): 510-540.

WCED-World Commission on Environment and Development. 1987. Our common future. UK and New York: Oxford University Press.

Zadek, Simon. 1999. Stalking sustainability. Greener Management International 26: 1-11.

Zarnekow, Rüdiger, and Koray Erek. 2008. Nachhaltiges IT-Servicemanagement: grundlagen. Vorgehensmodell und Managementinstrumente, HMD - Theorie und Praxis der Wirtschaftsinformatik 45(264): 7-18. 